\title{
Diatomáceas perifíticas em Potamogeton polygonus Cham. \& Schltdl.: citações pioneiras para o estado do Paraná
}

\author{
Eloési Machado dos Santos ${ }^{1}$, Priscila Izabel Tremarin ${ }^{1,2}$ \& Thelma Alvim Veiga Ludwig \\ ${ }^{1}$ Laboratório de Ficologia, Departamento de Botânica, Centro Politécnico, \\ Universidade Federal do Paraná - UFPR, CP 19031, CEP 81531-990, \\ Jardim das Américas, Curitiba, PA, Brasil \\ ${ }^{2}$ Autor para correspondência: Priscila Izabel Tremarin, e-mail: ptremarin@gmail.com
}

SANTOS, E.M., TREMARIN, P.I. \& LUDWIG, T.A.V. Periphytic diatoms on Potamogeton polygonus Cham. \& Schltdl.: first records from Paraná State. Biota Neotrop. 11(3): http://www.biotaneotropica.org.br/v11n3/ en/abstract?inventory+bn01611032011

\begin{abstract}
Periphytic diatoms on Potamogeton polygonus Cham. \& Schltdl.: first records from Paraná State. A taxonomic study of periphytic diatoms associated to aquatic macrophyte Potamogeton polygonus was carried out. Specimens were collected on February, May and November/2005 and March/2006, in an artificial lagoon and in the Salto Amazonas river, located at General Carneiro, Paraná State. Based on the analysis of permanent slides with cleaned periphytic samples, one hundred and forty-seven taxa had been registered, 55 diatoms were exclusive of the lentic environment, 34 of the lotic environment and 58 occurred on both ones. The most representative families were Eunotiaceae (13.6\%), Pinnulariaceae (11.6\%) and Naviculaceae (9.6\%). The genera with greater number of species and varieties were Eunotia with 20 taxa and Pinnularia with 17. The study contributed with 18 new registers to the state, and was pioneer to document forms of diatom attachment on aquatic macrophyte of systems lotic and lentic in the Paraná state.

Keywords: Bacillariophyta, macrophyte, periphyton, Salto Amazonas river, taxonomy.
\end{abstract}

SANTOS, E.M., TREMARIN, P.I. \& LUDWIG, T.A.V. Diatomáceas perifíticas em Potamogeton polygonus Cham. \& Schltdl.: citações pioneiras para o estado do Paraná. Biota Neotrop. 11(3): http://www. biotaneotropica.org.br/v11n3/pt/abstract?inventory+bn01611032011

Resumo: Diatomáceas perifíticas em Potamogeton polygonus Cham. \& Schltdl.: citações pioneiras para o Estado do Paraná. Realizou-se o estudo taxonômico das diatomáceas perifíticas associadas à macrófita aquática Potamogeton polygonus. Espécimes da macrófita foram coletados em fevereiro, maio e novembro/2005 e março/2006, em uma lagoa artificial e no rio Salto Amazonas, ambos localizados em fazendas no município de General Carneiro, Paraná. Baseados na análise de lâminas permanentes com material perifítico oxidado registraramse cento e quarenta e sete táxons, sendo 55 exclusivos do ambiente lêntico, 34 exclusivos do ambiente lótico e 58 observados em ambos locais. As famílias mais representativas foram Eunotiaceae (13,6\%), Pinnulariaceae $(11,6 \%)$ e Naviculaceae $(9,6 \%)$. Os gêneros com maior número de espécies e variedades foram Eunotia com 20 táxons e Pinnularia com 17. O estudo contribuiu com 18 novas citações para o Estado do Paraná.

Palavras-chave: Bacillariophyta, macrófita, perifíton, rio Salto Amazonas, taxonomia. 


\section{Introdução}

As macrófitas habitam a região litorânea de ambientes aquáticos lênticos e lóticos, podendo estar total ou parcialmente submersas ou flutuantes no meio aquático. Além de viabilizar a sobrevivência de uma extensa variedade de organismos aquáticos, disponibilizando alimento, refúgio e local para procriação, essa vegetação serve de substrato para o estabelecimento do perifíton (Burkholder 1996, Pompêo \& Moschini-Carlos 2003). Dentre os inúmeros substratos disponíveis para o estabelecimento da comunidade perifítica, as macrófitas aquáticas constituem o substrato natural com um dos maiores índices de abundância e riqueza de espécies de microorganismos. Algas encontram nessas plantas um local propício para seu desenvolvimento, sendo beneficiadas pelos compostos orgânicos e pelos nutrientes excretados pelas macrófitas, as quais de certa forma são protegidas dos organismos herbívoros pelo biofilme que se estabelece em sua superfície (Cattaneo \& Kalff 1979). É muito provável que haja interações significativas entre as epífitas e as macrófitas aquáticas que lhes servem de suporte, e que essas trocas metabólicas afetem a composição específica das algas, a dinâmica populacional relacionada com a sucessão e a produtividade resultante (Wetzel 1983).

As algas perifíticas têm papel relevante no metabolismo dos ambientes aquáticos como importante produtor primário e regulador do fluxo de nutrientes nestes ecossistemas (Pompêo \& MoschiniCarlos 2003). A representatividade das diatomáceas no perifíton, principalmente em ambientes lóticos, deve-se às adaptações morfológicas que favorecem sua fixação nos substratos (Esteves 1988). Campo de poros apicais, rimopórtula e rafe são as principais estruturas secretoras de mucilagem nesse grupo de algas. Em espécies planctônicas, a mucilagem permite a formação de cadeias e nas bentônicas, fixação ou deslocamento sobre o substrato (Round et al. 1990).

As diatomáceas destacam-se por ser um grupo amplamente diversificado e muito significativo em termos de riqueza de espécies. Trabalhos taxonômicos sobre diatomáceas perifíticas vêm avançando no estado Paraná, podendo-se destacar os estudos taxonômicos mais recentes: Leandrini et al. (2002), Landucci \& Ludwig (2005), Ludwig et al. (2005), Ferrari \& Ludwig (2007), Tremarin et al. (2008, 2009, 2010), Faria et al. (2010), Silva et al. (2010) e Bertolli et al. (2010).

Este estudo teve como objetivo inventariar as espécies e variedades taxonômicas de diatomáceas associadas à macrófita Potamogeton polygonus coletadas em ambientes lótico e lêntico, com ênfase aos primeiros registros para o Estado do Paraná. Além disso, pretendeu-se registrar a variação morfológica dos táxons, discutir a problemática taxonômica pertinente e contribuir para o conhecimento da diatomoflórula paranaense.

\section{Material e Métodos}

Espécimes da macrófita Potamogeton polygonus Cham. \& Schltdl. foram coletados e fixados em solução de Transeau. As coletas realizaram-se em fevereiro, maio e novembro/2005 e março/2006, no rio Salto Amazonas ( $26^{\circ} 21^{\prime}$ 6,2', S e 51 ${ }^{\circ} 36^{\prime}$ 51,6', O) e em uma lagoa artificial (26 $26^{\circ} 42,4^{\prime}$ ' $\mathrm{S}$ e $51^{\circ} 21^{\prime} 22,6^{\prime}$ ' O), ambos localizados em fazendas no município de General Carneiro, Paraná.

Para o estudo taxonômico foram coletados dois espécimes de cada ambiente, os quais passaram por um processo de raspagem manual com escovas de cerdas macias e água destilada. Lâminas permanentes com material oxidado foram confeccionadas segundo a técnica de Simonsen (1974) modificada por Moreira-Filho \& Valente-Moreira (1981). As ilustrações foram obtidas utilizando-se fotomicroscópio Olympus BX40 com câmera digital acoplada Olympus DP70. O sistema de classificação foi o proposto por Round et al. (1990). A terminologia utilizada nas descrições das frústulas foi embasada, principalmente, em Barber \& Haworth (1981).
As amostras e as respectivas lâminas permanentes foram depositadas no Herbário do Departamento de Botânica (UPCB), Setor de Ciências Biológicas da Universidade Federal do Paraná (Tabela 1).

\section{Resultados e Discussão}

A análise qualitativa das amostras (Tabela 2) provenientes do rio Salto Amazonas e de uma lagoa artificial, ambos localizados no município de General Carneiro/PR resultou na identificação de 147 táxons, entre os quais se incluem 127 espécies, 16 variedades que não as típicas, uma forma não típica e três táxons em nível genérico, enquadrados em 42 gêneros e incluídos em 23 famílias. O estudo contribuiu com 18 novas citações para o Estado do Paraná. As famílias mais representativas foram Eunotiaceae $(13,6 \%)$, Pinnulariaceae $(11,6 \%)$ e Naviculaceae $(9,6 \%)$. Os gêneros com maior número de espécies e variedades foram Eunotia com 20 táxons e Pinnularia com 17. No ambiente lêntico registrou-se maior riqueza de espécies e variedades taxonômicas (113) do que no lótico (92). Trinta e quatro táxons $(23,1 \%)$ ocorreram exclusivamente no ambiente lótico, 55 $(37,4 \%)$ no ambiente lêntico e $58(39,5 \%)$ de ocorrência comum aos dois ambientes.

Descrições e comentários dos táxons pioneiros para o estado do Paraná:

\section{Melosira sp. (Figuras 1-5)}

Frústulas cilíndricas em vista pleural; espinhos inconspícuos; manto com estriação inconspícua; valvas circulares; superfície valvar plana; margem valvar espessa; presença de granulações na região central; areolação inconspícua. Diâmetro: 5,3-7,6 $\mu \mathrm{m}$; altura: $8,7-11,9 \mu \mathrm{m}$.

Em vista valvar, Melosira sp. assemelha-se a outras espécies com pequenas dimensões do gênero, como Melosira dickiei (Thwaites) Kützing e M. astridae Metzeltin \& Lange-Bertalot. Estágios de resistência não foram observados. A determinação infragenérica dos exemplares não foi possível devido, principalmente, a diferenças na morfometria da frústula. $M$. dickiei possui diâmetro valvar de 10$20 \mu \mathrm{m}$ e manto com 7-10 $\mu \mathrm{m}$ de altura e $M$. astriadae, tem 6,5-14 $\mu \mathrm{m}$ de diâmetro e manto com 3-4 $\mu$ m de altura, além de apresentar superfície valvar ornamentada por grânulos e espinhos (Krammer \& Lange-Bertalot 1991a, Metzeltin \& Lange-Bertalot 2007).

Eunotia aff. donatoi Metzeltin \& Lange-Bertalot, Iconogr. Diatomol. 18: 91, pl. 97, figs 4-7, 2007. (Figuras 9-10)

Valvas com margem dorsal convexa, margem ventral reta a ligeiramente côncava; extremidades subcapitadas, destacadas do corpo valvar; nódulos terminais largos, localizados nas extremidades; estrias conspícuas, paralelas na região mediana da valva, levemente radiadas nas extremidades; aréolas inconspícuas. Comprimento: 40,370,0 $\mu \mathrm{m}$; largura: 5,0-6,4 $\mu \mathrm{m}$; estrias: 9-11 em $10 \mu \mathrm{m}$.

Tabela 1. Dados das coletas realizadas no município de General Carneiro, Estado do Paraná, e número de registro das amostras no Herbário da Universidade Federal do Paraná (UPCB).

Table 1. Data from samplings made in the General Carneiro municipality, Paraná State, and registration number of samples in the Herbarium of Parana Federal University (UPCB).

\begin{tabular}{lccl}
\hline \multicolumn{1}{c}{ Local } & Data & UPCB & \multicolumn{1}{c}{ Coletor } \\
\hline rio Salto Amazonas & $21 / \mathrm{II} / 2005$ & 53795 & Santos, E.M. s.n. \\
rio Salto Amazonas & $23 / \mathrm{V} / 2005$ & 53809 & Santos, E.M. s.n. \\
rio Salto Amazonas & $03 / \mathrm{XI} / 2005$ & 53812 & Santos, E.M. s.n. \\
rio Salto Amazonas & $07 / \mathrm{III} / 2006$ & 53822 & Santos, E.M. s.n. \\
lagoa artificial & $22 / \mathrm{II} / 2005$ & 53801 & Santos, E.M. s.n. \\
lagoa artificial & $24 / \mathrm{V} / 2005$ & 53811 & Santos, E.M. s.n. \\
lagoa artificial & $01 / \mathrm{XI} / 2005$ & 53819 & Santos, E.M. s.n. \\
lagoa artificial & $06 / \mathrm{II} / 2006$ & 53826 & Santos, E.M. s.n. \\
\hline
\end{tabular}


Diatomáceas epifíticas em Potamogeton polygonus Cham. \& Schltdl.

Tabela 2. Lista de espécies encontradas nas amostras, limites métricos e ocorrência nas amostras.

Table 2. List of species found in the samples, metrical boundaries and occurrence in the samples.

\begin{tabular}{|c|c|c|c|}
\hline \multirow[t]{2}{*}{ Famílias/espécies } & \multicolumn{2}{|c|}{ Dados merísticos } & \multirow{2}{*}{$\begin{array}{c}\text { Número de registro } \\
\text { das amostras (UPCB) }\end{array}$} \\
\hline & $\mu \mathrm{m}$ & em $10 \mu \mathrm{m}$ & \\
\hline MELOSIRACEAE & & & \\
\hline Melosira sp. & $5,3-7,6^{\mathrm{d}} / 8,7-11,9^{\mathrm{h}}$ & & $53811 ; 53826$ \\
\hline AULACOSEIRACEAE & & & \\
\hline $\begin{array}{l}\text { Aulacoseira alpigena } \\
\text { (Grunow) Krammer }\end{array}$ & $6,7-7,9^{\mathrm{d}} / 4,8^{\mathrm{h}}$ & $12-14^{\mathrm{e}} / 14^{\mathrm{a}}$ & 53795 \\
\hline ORTHOSEIRACEAE & & & \\
\hline $\begin{array}{l}\text { Orthoseira dendroteres } \\
\text { (Ehrenberg) Crawford }\end{array}$ & $10,6-13,6^{\mathrm{d}} / 19,0-26,1^{\mathrm{h}}$ & $15-18^{\mathrm{e}} / 18^{\mathrm{a}}$ & $53795 ; 53809 ; 53811 ; 53822$ \\
\hline FRAGILARIACEAE & & & \\
\hline $\begin{array}{l}\text { Fragilaria capucina Desmazières } \\
\text { var. capucina }\end{array}$ & $37,3-52,8^{c} / 4,3-5,7^{1}$ & $15-16^{\mathrm{e}}$ & $53795 ; 53801 ; 53809 ; 53812 ; 53822$ \\
\hline $\begin{array}{l}\text { Fragilaria capucina var. } \\
\text { fragilarioides }(\text { Grunow) } \\
\text { Ludwig \& Flôres }\end{array}$ & $29,3-35,3^{\mathrm{c}} / 4,0-4,7^{1}$ & $13-14^{\mathrm{e}}$ & $53795 ; 53809$ \\
\hline $\begin{array}{l}\text { Fragilaria capucina var. gracilis } \\
\text { (Östrup) Hustedt }\end{array}$ & $41,9-60,0^{c} / 1,8-2,4^{1}$ & $18^{\mathrm{e}}$ & $53795 ; 53801 ; 53811 ; 53819$ \\
\hline $\begin{array}{l}\text { Fragilaria capucina var. } \\
\text { meneghiniana (Grunow) }\end{array}$ & $16,8-28,8^{c} / 4,8-6,0^{1}$ & $12-14^{\mathrm{e}}$ & $53795 ; 53809 ; 53822$ \\
\hline Ludwig \& Flôres & & & \\
\hline $\begin{array}{l}\text { Fragilaria capucina } \\
\text { var. mesolepta } \text { Rabenhorst }\end{array}$ & $30,0-38,4^{\mathrm{c}} / 3,9-4,0^{1}$ & $14-15^{\mathrm{e}}$ & $53795 ; 53801 ; 53809$ \\
\hline $\begin{array}{l}\text { Fragilaria capucina var. vaucheriae } \\
\text { (Kützing) Lange-Bertalot }\end{array}$ & $13,3-22,1^{c} / 4,7-6,3^{1}$ & $11-14^{\mathrm{e}}$ & $53795 ; 53812 ; 53819 ; 53822$ \\
\hline Fragilaria javanica Hustedt & $4,6-4,8^{1}$ & $16-17^{\mathrm{e}}$ & $53795 ; 53801$ \\
\hline Ulnaria acus (Kützing) Aboal & $76,6-128,0^{\mathrm{c}} / 4,7-7,1^{1}$ & $12-14^{\mathrm{e}}$ & $53795 ; 53809$ \\
\hline Ulnaria ulna (Nitzsch) Compère & $110,6-372,1^{\mathrm{c}} / 7,1-8,7^{1}$ & $7-9^{e}$ & $\begin{array}{c}53795 ; 53809 ; 53811 ; \\
53812 ; 53822 ; 53826\end{array}$ \\
\hline $\begin{array}{l}\text { Meridion circulare var. } \\
\text { constrictum (Ralfs) Van Heurck }\end{array}$ & $23,7-40,7^{c} / 4,7-5,5^{1}$ & $15-16^{\mathrm{e}}$ & $53795 ; 53809$ \\
\hline EUNOTIACEAE & & & \\
\hline $\begin{array}{l}\text { Desmogonium transfugum } \\
\text { (Metzeltin \& Lange-Bertalot) }\end{array}$ & $139,0-216,5^{\mathrm{c}} / 7,9-8,7^{1}$ & $14-16^{\mathrm{e}} 16^{\mathrm{a}}$ & 53811 \\
\hline Metzeltin \& Lange-Bertalot & & & \\
\hline $\begin{array}{l}\text { Eunotia bilunaris (Ehrenberg) } \\
\text { Souza }\end{array}$ & $14,6-47,7^{c} / 3,3-4,6^{1}$ & $18-20^{\mathrm{e}}$ & $53795 ; 53809 ; 53812 ; 53822$ \\
\hline $\begin{array}{l}\text { Eunotia bilunaris var. linearis } \\
\text { (Okuno) Lange-Bertalot \& Nörpel }\end{array}$ & $70,0-150,1^{\mathrm{c}} / 3,3-3,9^{1}$ & $12-13^{\mathrm{e}}$ & $53801 ; 53811 ; 53819 ; 53826$ \\
\hline Eunotia camelus Ehrenberg & $32,8-46,6^{c} / 6,0-6,7^{1}$ & $9-10^{\mathrm{e}}$ & $53801 ; 53811 ; 53826$ \\
\hline Eunotia aff. donatoi & $40,3-70,0^{c} / 5,0-6,4^{1}$ & $9-11^{\mathrm{e}}$ & $\begin{array}{c}53795 ; 53801 ; 53809 ; \\
53811 ; 53812 ; 53822 ; 53826\end{array}$ \\
\hline Eunotia faba (Ehrenberg) Grunow & $47,4^{\mathrm{c}} / 6,3^{1}$ & $14^{\mathrm{e}}$ & 53809 \\
\hline Eunotia flexuosa Brébisson & $130,3-230,4^{\mathrm{c}} / 4,0-4,8^{1}$ & $16-18^{\mathrm{e}}$ & $53801 ; 53811$ \\
\hline Eunotia incisa Gregory & $14,6-24,0^{\mathrm{c}} / 3,3-4,0^{1}$ & $12-14^{\mathrm{e}}$ & $53809 ; 53819 ; 53822$ \\
\hline $\begin{array}{l}\text { Eunotia maior (W. Smith) } \\
\text { Rabenhorst }\end{array}$ & $111,4-112,7^{c} / 8,7-9,3^{1}$ & $8^{\mathrm{e}} / 18^{\mathrm{a}}$ & 53826 \\
\hline $\begin{array}{l}\text { Eunotia meridiana Metzeltin \& } \\
\text { Lange-Bertalot }\end{array}$ & $16,0-32,8^{c} / 4,0-5,6^{1}$ & $10-12^{\mathrm{e}} / 20-24^{\mathrm{a}}$ & $53795 ; 53801 ; 53809 ; 53812 ; 53822$ \\
\hline Eunotia minor (Kützing) Grunow & $15,8-43,6^{\mathrm{c}} / 4,0-7,2^{1}$ & $12-16^{\mathrm{e}}$ & $\begin{array}{c}53795 ; 53801 ; 53809 ; \\
53811 ; 53812 ; 53822 ; 53826\end{array}$ \\
\hline Eunotia monodon Ehrenberg & $57,7-64,8^{\mathrm{c}} / 9,0-9,5^{1}$ & $9-10^{\mathrm{e}} 18^{\mathrm{a}}$ & $53809 ; 53822$ \\
\hline Eunotia naegelii Migula & $31,2-118,2^{\mathrm{c}} / 2,4-3,8^{1}$ & $16-18^{\mathrm{e}}$ & $\begin{array}{l}53795 ; 53801 ; 53809 ; 53811 ; \\
53812 ; 53819 ; 53822 ; 53826\end{array}$ \\
\hline Eunotia paludosa Grunow & $21,3-24,7^{c} / 2,7-3,3^{1}$ & $15-18^{\mathrm{e}}$ & 53819 \\
\hline $\begin{array}{l}\text { Eunotia pseudosudetica Metzeltin, } \\
\text { Lange-Bertalot \& García-Rodríguez }\end{array}$ & $25,8-28,0^{c} / 4,3-5,8^{1}$ & $9-14^{\mathrm{e}}$ & $\begin{array}{l}53795 ; 53801 ; 53809 ; 53811 ; \\
53812 ; 53819 ; 53822 ; 53826\end{array}$ \\
\hline
\end{tabular}

Nota: comprimento (c), largura (l), diâmetro (d), altura valvar (h), estrias (e), estrias dorsais (ed), estrias ventrais (ev), aréolas (a), fíbulas (f), projeções aliformes (pa), (vr) valva com rafe, (vsr) valva sem rafe. 
Tabela 2. Continuação.

Table 2. Continued.

\begin{tabular}{|c|c|c|c|}
\hline \multirow[t]{2}{*}{ Famílias/espécies } & \multicolumn{2}{|c|}{ Dados merísticos } & \multirow{2}{*}{$\begin{array}{c}\text { Número de registro } \\
\text { das amostras (UPCB) }\end{array}$} \\
\hline & $\mu \mathrm{m}$ & em $10 \mu \mathrm{m}$ & \\
\hline Eunotia pyramidata Hustedt & $29,2-67,2^{\mathrm{c}} / 7,9-8,7^{1}$ & $11-12^{\mathrm{e}}$ & $53795 ; 53809 ; 53812$ \\
\hline $\begin{array}{l}\text { Eunotia rabenhorstii } \\
\text { Cleve \& Grunow }\end{array}$ & $14,2-31,2^{c} / 6,3-8,8^{1}$ & $11-13^{\mathrm{e}}$ & $53795 ; 53801 ; 53811 ; 53826$ \\
\hline Eunotia aff. siolii Hustedt & $19,6-20,5^{c} / 4,0-4,7^{1}$ & $8-9^{e}$ & $53795 ; 53826$ \\
\hline Eunotia sudetica Müller & $34,0-42,0^{c} / 6,7-7,3^{1}$ & $10-11^{\mathrm{e}}$ & $53809 ; 53812 ; 53819 ; 53826$ \\
\hline Eunotia veneris (Kützing) De Toni & $32,4-43,5^{c} / 6,3-7,9^{1}$ & $8-11^{\mathrm{e}}$ & $53809 ; 53812 ; 53819 ; 53826$ \\
\hline $\begin{array}{l}\text { Cymbopleura naviculiformis } \\
\text { (Auerswald) Krammer }\end{array}$ & $30,0-35,6^{c} / 7,9-9,5^{1}$ & $9-12^{\mathrm{ed}} / 12-14^{\mathrm{ev}}$ & $53801 ; 53811$ \\
\hline $\begin{array}{l}\text { Encyonema neogracile var. } \\
\text { tenuipunctata Krammer }\end{array}$ & $36,0-56,8^{c} / 4,8-9,2^{1}$ & $12-14^{\mathrm{ed}, \mathrm{ev}} / 32^{\mathrm{a}}$ & $53795 ; 53801 ; 53811 ; 53819 ; 53826$ \\
\hline Encyonema neomesianum Krammer & $33,6-48,0^{\mathrm{c}} / 7,2-8,8^{1}$ & $7-10^{\mathrm{ed}} / 8-12^{\mathrm{ev}} / 22^{\mathrm{a}}$ & $53801 ; 53809 ; 53811 ; 53819 ; 53826$ \\
\hline $\begin{array}{l}\text { Encyonema perpusillum } \\
\text { (Cleve) Mann }\end{array}$ & $11,9-15,0^{\mathrm{c}} / 4,0^{1}$ & $11-12^{\mathrm{ed}} / 10-12^{\mathrm{ev}}$ & $53809 ; 53822$ \\
\hline Encyonema riotecense Krammer & $37,1-40,7^{c} / 7,8-9,2^{1}$ & $11-12^{\text {ed, ev }}$ & $53811 ; 53819$ \\
\hline $\begin{array}{l}\text { Encyonema silesiacum } \\
\text { (Bleisch) Mann }\end{array}$ & $17,6-32,8^{c} / 4,8-8,0^{1}$ & $8-14^{\mathrm{ed}} / 10-14^{\mathrm{ev}}$ & $\begin{array}{c}53795 ; 53801 ; 53809 ; 53811 ; 53812 \\
53819 ; 53822 ; 53826\end{array}$ \\
\hline $\begin{array}{l}\text { Encyonopsis kaingensis } \\
\text { (Vyverman) Krammer }\end{array}$ & $26,1-40,6^{c} / 3,2-4,8^{1}$ & $10-11^{\text {ed, ev }}$ & 53809 \\
\hline $\begin{array}{l}\text { Encyonopsis subminuta } \\
\text { Krammer \& Reichardt }\end{array}$ & $16,0-20,8^{c} / 3,2-4,8^{1}$ & $24^{\mathrm{e}}$ & $53795 ; 53801 ; 53811 ; 53819$ \\
\hline Encyonopsis sp. & $15,8-25,6^{c} / 5,5-6,4^{1}$ & $10-12^{\mathrm{ed}} / 9-10^{\mathrm{ev}}$ & $53795 ; 53801 ; 53809 ; 53811$ \\
\hline $\begin{array}{l}\text { Placoneis exigua (Gregory) } \\
\text { Mereschkowsky }\end{array}$ & $30,7^{c} / 10,7^{1}$ & $11^{\mathrm{e}}$ & 53801 \\
\hline GOMPHONEMATACEAE & & & \\
\hline Gomphonema auritum Braun & $21,3-35,5^{\mathrm{c}} / 4,0-4,7^{1}$ & $10-14^{\mathrm{e}}$ & $53795 ; 53801 ; 53809 ; 53811 ; 53822$ \\
\hline Gomphonema gracile Ehrenberg & $43,5-84,5^{\mathrm{c}} / 7,9-11,3^{1}$ & $8-11^{\mathrm{e}} / 24^{\mathrm{a}}$ & $\begin{array}{c}53795 ; 53801 ; 53809 ; 53811 ; 53812 \\
53819 ; 53822 ; 53826\end{array}$ \\
\hline Gomphonema lagenula Kützing & $15,8-23,1^{c} / 4,3-7,1^{1}$ & $11-15^{\mathrm{e}}$ & $53795 ; 53809 ; 53811 ; 53819 ; 53822$ \\
\hline $\begin{array}{l}\text { Gomphonema parvulum } \\
\text { (Kützing) Kützing }\end{array}$ & $10,3-24,8^{c} / 3,2-4,0^{1}$ & $12-16^{\mathrm{e}}$ & $\begin{array}{l}53795 ; 53801 ; 53809 ; 53811 ; \\
53812 ; 53819 ; 53822 ; 53826\end{array}$ \\
\hline $\begin{array}{l}\text { Gomphonema pseudoaugur } \\
\text { Lange-Bertalot }\end{array}$ & $26,4-38,4^{\mathrm{c}} / 7,1-8,0^{1}$ & $11-14^{\mathrm{e}}$ & $53795 ; 53809 ; 53812 ; 53822$ \\
\hline $\begin{array}{l}\text { Gomphonema subtile Ehrenberg } \\
\text { COCCONEIDACEAE }\end{array}$ & $53,6-60,0^{c} / 6,4-8,0^{1}$ & $7-10^{\mathrm{e}}$ & $53801 ; 53811 ; 53826$ \\
\hline $\begin{array}{l}\text { Cocconeis placentula } \\
\text { var. acuta Meister }\end{array}$ & $41,9-49,0^{\mathrm{c}} / 20,5-22,0^{1}$ & $18-19^{\mathrm{e}}$ & $53811 ; 53826$ \\
\hline $\begin{array}{l}\text { Cocconeis placentula var. lineata } \\
\text { (Ehrenberg) Van Heurck }\end{array}$ & 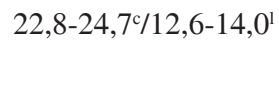 & $18^{\mathrm{e}}$ & $53809 ; 53812$ \\
\hline ACHNANTHIDIACEAE & & & \\
\hline $\begin{array}{l}\text { Achnanthidium exiguum } \\
\text { (Grunow) Czarnecki }\end{array}$ & $16,7^{c} / 7,3^{1}$ & $14^{\mathrm{e}}$ & 53822 \\
\hline $\begin{array}{l}\text { Achnanthidium minutissimum } \\
\text { (Kützing) Czarnecki }\end{array}$ & $7,9-18,2^{c} / 2,4-3,2^{1}$ & & $\begin{array}{c}53795 ; 53801 ; 53809 ; 53811 ; 53812 \\
53819 ; 53822 ; 53826\end{array}$ \\
\hline Achnanthidium sp. & $7,9-11,1^{\mathrm{c}} / 3,2-4,0^{1}$ & $18-20^{\mathrm{vr}} / 18-24^{\mathrm{vsr}}$ & $53795 ; 53809 ; 53811 ; 53826$ \\
\hline $\begin{array}{l}\text { Lemnicola hungarica (Grunow) } \\
\text { Round \& Basson }\end{array}$ & $14,2-34,8^{c} / 5,6-7,8^{1}$ & $18-24^{\mathrm{e}}$ & $53795 ; 53801 ; 53809$ \\
\hline $\begin{array}{l}\text { Planothidium dubium (Grunow) } \\
\text { Round \& Bukhtiyarova }\end{array}$ & $19,0^{c} / 7,9^{1}$ & $11^{\mathrm{e}}$ & 53811 \\
\hline $\begin{array}{l}\text { Planothidium heteromorphum } \\
\text { (Grunow) Lange-Bertalot }\end{array}$ & $25,3-33,3^{\mathrm{c}} / 12,6-14,7^{1}$ & $10-11^{\mathrm{vr}} / 9-11^{\mathrm{vsr}} / 18^{\mathrm{a}}$ & $53795 ; 53812$ \\
\hline $\begin{array}{l}\text { Planothidium lanceolatum } \\
\text { (Brébisson) Round \& Buhktiyarova }\end{array}$ & $14,2-16,6^{c} / 6,3-6,9^{1}$ & $12^{\mathrm{vr}} / 12-13^{\mathrm{vsr}}$ & 53811 \\
\hline
\end{tabular}

Nota: comprimento (c), largura (1), diâmetro (d), altura valvar (h), estrias (e), estrias dorsais (ed), estrias ventrais (ev), aréolas (a), fíbulas (f), projeções aliformes (pa), (vr) valva com rafe, (vsr) valva sem rafe. 
Tabela 2. Continuação.

Table 2. Continued.

\begin{tabular}{|c|c|c|c|}
\hline \multirow[t]{2}{*}{ Famílias/espécies } & \multicolumn{2}{|c|}{ Dados merísticos } & \multirow{2}{*}{$\begin{array}{l}\text { Número de registro } \\
\text { das amostras (UPCB) }\end{array}$} \\
\hline & $\mu \mathrm{m}$ & em $10 \mu \mathrm{m}$ & \\
\hline $\begin{array}{l}\text { Psammothidium subatomoides } \\
\text { (Hustedt) Bukhtiyarova \& Round }\end{array}$ & $8,7-10,3^{\mathrm{c}} / 4,0-4,7^{1}$ & & $53795 ; 53809 ; 53812 ; 53822$ \\
\hline \multicolumn{4}{|l|}{ CAVINULACEAE } \\
\hline Cavinula lapidosa (Krasske) & $23,7^{c} / 10,3^{1}$ & & 53809 \\
\hline Lange-Bertalot & & & \\
\hline \multicolumn{4}{|l|}{ DIADESMIDACEAE } \\
\hline $\begin{array}{l}\text { Diadesmis contenta } \\
\text { (Grunow) Mann }\end{array}$ & $6,3-11,9^{c} / 2,4-3,2^{1}$ & & 53801; 53809; 53811; 53819 \\
\hline $\begin{array}{l}\text { Diadesmis implicata Moser, } \\
\text { Lange-Bertalot \& Metzeltin }\end{array}$ & $8,3-11,9^{c} / 2,7-3,2^{1}$ & & 53811 \\
\hline $\begin{array}{l}\text { Diadesmis pseudolangebertalotii } \\
\text { Metzeltin, Lange-Betalot \& } \\
\text { García-Rodríguez }\end{array}$ & $10,1-14,3^{\mathrm{c}} / 3,3-3,5^{1}$ & & 53811 \\
\hline $\begin{array}{l}\text { Luticola dapaloides } \\
\text { (Frenguelli) Lange-Bertalot }\end{array}$ & $87,7 \mathrm{c} / 22,9^{1}$ & $12^{\mathrm{e}} / 10^{\mathrm{a}}$ & 53811 \\
\hline $\begin{array}{l}\text { Luticola goeppertiana } \\
\text { (Bleisch) Mann }\end{array}$ & $18,2-30,0^{c} / 6,2-7,1^{1}$ & $20-22^{\mathrm{e}} / 24^{\mathrm{a}}$ & $53795 ; 53809 ; 53811 ; 53822 ; 53826$ \\
\hline Luticola lagerheimii (Cleve) Mann & $22,1-25,0^{c} / 7,1-7,9^{1}$ & $18^{\mathrm{e}} / 18^{\mathrm{a}}$ & 53809 \\
\hline Luticola mutica (Kützing) Mann & $14,7-19,7^{c} / 5,3-6,3^{1}$ & $18-20^{\mathrm{e}} / 20-22^{\mathrm{a}}$ & $53795 ; 53809 ; 53811$ \\
\hline $\begin{array}{l}\text { Luticola muticoides } \\
\text { (Hustedt) Mann }\end{array}$ & $12,5-20,7^{c} / 7,1-8,6^{1}$ & $18-20^{\mathrm{e}} / 24^{\mathrm{a}}$ & $53801 ; 53809 ; 53811 ; 5381253819$ \\
\hline \multicolumn{4}{|l|}{ AMPHIPLEURACEAE } \\
\hline Amphipleura lindheimerii Grunow & $201,2^{c} / 25,0^{1}$ & $22^{\mathrm{et}} / 20^{\mathrm{el}}$ & 53811 \\
\hline $\begin{array}{l}\text { Frustulia crassinervia } \\
\text { (Brébisson) Costa }\end{array}$ & $50,0-79,0^{c} / 11,3-16,0^{1}$ & $26^{\mathrm{et}} / 24^{\mathrm{el}}$ & $\begin{array}{c}53795 ; 53801 ; 53809 ; 53811 ; 53812 \\
53819 ; 53822 ; 53826\end{array}$ \\
\hline $\begin{array}{l}\text { Frustulia neomundana } \\
\text { Lange-Bertalot \& Rumrich }\end{array}$ & $33,3-35,0^{\mathrm{c}} / 8,0-8,5^{1}$ & & $53795 ; 53809$ \\
\hline Frustulia saxonica Rabenhorst & $85,6-87,6^{c} / 18,1-19,7^{1}$ & & $53795 ; 53801 ; 53809 ; 53822$ \\
\hline \multicolumn{4}{|l|}{ BRACHYSIRACEAE } \\
\hline Brachysira brebissonii Ross & $15,8-22,1^{c} / 4,7-6,3^{1}$ & $20-22^{\mathrm{e}}$ & $53801 ; 53811 ; 53812$ \\
\hline Brachysira vitrea (Grunow) Ross & $12,0-29,6^{c} / 4,0-5,6^{1}$ & & $\begin{array}{c}53795 ; 53801 ; 53809 ; 53811 ; \\
53812 ; 53819 ; 53826\end{array}$ \\
\hline \multicolumn{4}{|l|}{ NEIDIACEAE } \\
\hline Neidium affine (Ehrenberg) Pfitzer & $42,7-52,8^{c} / 9,5-11,2^{1}$ & $18^{\mathrm{e}}$ & $53801 ; 53811$ \\
\hline $\begin{array}{l}\text { Neidium ampliatum } \\
\text { (Ehrenberg) Krammer }\end{array}$ & $56,8-80,8^{c} / 15,2-16,0^{1}$ & $18-24^{e} / 15-18^{a}$ & 53801 \\
\hline $\begin{array}{l}\text { Neidium catarinense (Krasske) } \\
\text { Lange-Bertalot }\end{array}$ & $19,7^{c} / 4,7^{1}$ & $24^{\mathrm{e}}$ & 53801 \\
\hline Neidium hercynicum Mayer & $22,1-25,3^{c} / 5,5-6,3^{1}$ & $26^{\mathrm{e}}$ & $53809 ; 53811$ \\
\hline Neidium improvisum & $29,2-37,1^{c} / 7,1-8,7^{1}$ & $26^{\mathrm{e}}$ & $53809 ; 53822$ \\
\hline \multicolumn{4}{|l|}{ SELLAPHORACEAE } \\
\hline $\begin{array}{l}\text { Sellaphora capitata Mann \& } \\
\text { McDonald }\end{array}$ & $23,2-28,0^{c} / 7,1-7,9^{1}$ & $17-21^{\mathrm{e}}$ & $53801 ; 53811$ \\
\hline $\begin{array}{l}\text { Sellaphora pseudopupula } \\
\text { (Krasske) Lange-Bertalot }\end{array}$ & $14,2-30,0^{\mathrm{c}} / 5,5-6,3^{1}$ & $24^{\mathrm{e}}$ & 53811 \\
\hline $\begin{array}{l}\text { Sellaphora rectangularis } \\
\text { (Gregory) Lange-Bertalot }\end{array}$ & $34,8-41,9^{\mathrm{c}} / 7,1-8,7^{1}$ & $18^{\mathrm{e}}$ & $53795 ; 53809 ; 53811 ; 53826$ \\
\hline $\begin{array}{l}\text { Sellaphora seminulum } \\
\text { (Grunow) Mann }\end{array}$ & $4,7-10,0^{c} / 3,2-4,0^{1}$ & $20-22^{\mathrm{e}}$ & $53811 ; 53822$ \\
\hline $\begin{array}{l}\text { Sellaphora ventraloconfusa } \\
\text { (Lange-Bertalot) } \\
\text { Metzeltin \& Lange-Bertalot }\end{array}$ & $22,1-22,9^{\mathrm{c}} / 5,5-6,3^{1}$ & $20-24^{\mathrm{e}}$ & 53811 \\
\hline
\end{tabular}

Nota: comprimento (c), largura (l), diâmetro (d), altura valvar (h), estrias (e), estrias dorsais (ed), estrias ventrais (ev), aréolas (a), fíbulas (f), projeções aliformes (pa), (vr) valva com rafe, (vsr) valva sem rafe. 
Tabela 2. Continuação.

Table 2. Continued.

\begin{tabular}{|c|c|c|c|}
\hline \multirow[t]{2}{*}{ Famílias/espécies } & \multicolumn{2}{|c|}{ Dados merísticos } & \multirow{2}{*}{$\begin{array}{c}\text { Número de registro } \\
\text { das amostras (UPCB) }\end{array}$} \\
\hline & $\mu \mathrm{m}$ & em $10 \mu \mathrm{m}$ & \\
\hline \multicolumn{4}{|l|}{ PINNULARIACEAE } \\
\hline $\begin{array}{l}\text { Pinnularia acrosphaeria } \\
\text { W. Smith var. acrosphaeria }\end{array}$ & $81,4-103,5^{\mathrm{c}} / 12,6-15,2^{1}$ & $10-12^{\mathrm{e}}$ & 53801; 53809; 53811; 53819; 53826 \\
\hline Pinnularia biceps Gregory & $55,3-65,3^{c} / 9,5-10,8^{1}$ & $11-12^{\mathrm{e}}$ & $53801 ; 53811 ; 53812$ \\
\hline $\begin{array}{l}\text { Pinnularia borealis var. scalaris } \\
\text { (Ehrenberg) Rabenhorst }\end{array}$ & $48,9^{c} / 8,8^{1}$ & $5^{\mathrm{e}}$ & 53801 \\
\hline $\begin{array}{l}\text { Pinnularia brauniana } \\
\text { (Grunow) Mills }\end{array}$ & $33,6-57,6^{c} / 7,1-8,8^{1}$ & $10-12^{\mathrm{e}}$ & $53795 ; 53801 ; 53811 ; 53822 ; 53826$ \\
\hline Pinnularia gibba Ehrenberg & $64,8-71,3^{c} / 9,2-10,4^{1}$ & $10-11^{\mathrm{e}}$ & $53795 ; 53801 ; 53811 ; 53822$ \\
\hline $\begin{array}{l}\text { Pinnularia hudsonii Metzeltin, } \\
\text { Lange-Bertalot \& García-Rodríguez }\end{array}$ & $85,3-90,6^{c} / 10,7-11,8^{1}$ & $9-10^{\mathrm{e}}$ & 53811 \\
\hline Pinnularia inconstans Mayer & $42,0^{c} / 7,8^{1}$ & $12^{\mathrm{e}}$ & 53826 \\
\hline $\begin{array}{l}\text { Pinnularia microstauron } \\
\text { (Ehrenberg) Cleve }\end{array}$ & $33,0-37,1^{\mathrm{c}} / 6,3-8,8^{1}$ & $14-15^{\mathrm{e}}$ & $53801 ; 53811$ \\
\hline Pinnularia neomajor Krammer & $\begin{array}{c}230,4-247,2^{c} / \\
31,6-36,8^{1}\end{array}$ & $5-7^{e}$ & $53801 ; 53811 ; 53819 ; 53826$ \\
\hline Pinnularia schoenfelderi Krammer & $21,3-30,0^{\mathrm{c}} / 4,0-5,5^{1}$ & $12-14^{\mathrm{e}}$ & $53795 ; 53809$ \\
\hline Pinnularia tabellaria Ehrenberg & $72,0-103,2^{\mathrm{c}} / 11,2-14,4^{1}$ & $12-14^{\mathrm{e}}$ & $53801 ; 53811 ; 53826$ \\
\hline $\begin{array}{l}\text { Pinnularia viridis (Nitzsch) } \\
\text { Ehrenberg }\end{array}$ & $80,8-121,6^{c} / 13,4-22,2^{1}$ & $8-9^{e}$ & $53795 ; 53801 ; 53812$ \\
\hline Pinnularia oominensis Kobayashi & $20,5^{\mathrm{c}} / 4,0^{1}$ & $12^{\mathrm{e}}$ & $53795 ; 53809$ \\
\hline Pinnularia sp.1 & $43,4-57,6^{c} / 8,0-9,3^{1}$ & $10-12^{\mathrm{e}}$ & $53801 ; 53811$ \\
\hline Pinnularia sp. 2 & $36,0-56,8^{c} / 5,6-8,8^{1}$ & $9-14^{\mathrm{e}}$ & $\begin{array}{l}53795 ; 53801 ; 53811 ; \\
53819 ; 53822 ; 53826\end{array}$ \\
\hline Pinnularia sp. 3 & $19,0^{c} / 4,7^{1}$ & $14^{\mathrm{e}}$ & 53809 \\
\hline Pinnularia sp. 4 & $44,2^{\mathrm{c}} / 8,1^{1}$ & $10^{\mathrm{e}}$ & 53822 \\
\hline Caloneis hyalina Hustedt & $12,8-21,3^{\mathrm{c}} / 3,2-5,5^{1}$ & $24^{\mathrm{e}}$ & $53801 ; 53811$ \\
\hline DIPLONEIDACEAE & & & \\
\hline Diploneis ovalis (Hilse) Cleve & $28,6-31,3^{c} / 17,3-18,2^{1}$ & $12^{\mathrm{e}} / 16^{\mathrm{a}}$ & 53811 \\
\hline Diploneis subovalis Cleve & $19,8-28,4^{c} / 13,6-17,4^{1}$ & $10^{\mathrm{e}} / 24^{\mathrm{a}}$ & $53801 ; 53811$ \\
\hline NAVICULACEAE & & & \\
\hline $\begin{array}{l}\text { Eolimna lepidula (Manguin) } \\
\text { Metzeltin \& Lange-Bertalot }\end{array}$ & $11,0-11,9^{c} / 4,7^{1}$ & $18^{\mathrm{e}}$ & 53819 \\
\hline Navicula angusta Grunow & $40,7^{c} / 6,0^{1}$ & $13^{\mathrm{e}}$ & 53895 \\
\hline Navicula cryptocephala Kützing & $25,3-37,1^{\mathrm{c}} / 4,7-5,5^{1}$ & $12-16^{\mathrm{e}}$ & $\begin{array}{c}53795 ; 53801 ; 53809 ; 53811 ; 53812 ; \\
53819 ; 53822 ; 53826\end{array}$ \\
\hline $\begin{array}{l}\text { Navicula cryptotenella } \\
\text { Lange-Bertalot }\end{array}$ & $22,1-22,9^{c} / 4,7-5,5^{1}$ & $15-18^{\mathrm{e}}$ & $\begin{array}{c}53795 ; 53801 ; 53809 ; 53811 ; 53812 ; \\
53819 ; 53822 ; 53826\end{array}$ \\
\hline $\begin{array}{l}\text { Navicula lohmanii } \\
\text { Lange-Bertalot \& Rumrich }\end{array}$ & $51,4-65,6^{\mathrm{c}} / 8,0-9,5^{1}$ & $12-14^{\mathrm{e}} / 20^{\mathrm{a}}$ & $53795 ; 53809 ; 53811 ; 53812 ; 53822$ \\
\hline $\begin{array}{l}\text { Navicula radiosa } \\
\text { var. parva Wallace }\end{array}$ & $37,1-45,0^{c} / 6,3-7,0^{1}$ & $14-16^{\mathrm{e}} / 24^{\mathrm{a}}$ & $\begin{array}{c}53795 ; 53809 ; 53811 ; 53812 ; 53819 ; \\
53822\end{array}$ \\
\hline Navicula salinicola Hustedt & $14,0-15,3^{\mathrm{c}} / 3,3-3,7^{1}$ & $20^{\mathrm{e}}$ & 53801 \\
\hline Navicula simulata Manguin & $33,2-34,8^{c} / 7,1^{1}$ & $14-15^{\mathrm{e}}$ & 53811 \\
\hline Navicula tridentula Krasske & $12,3-15,8^{\mathrm{c}} / 3,2^{1}$ & & $53801 ; 53811 ; 53826$ \\
\hline $\begin{array}{l}\text { Adlafia drouetiana (Patrick) } \\
\text { Metzeltin \& Lange-Bertalot }\end{array}$ & $17,4-24,0^{c} / 4,7-6,0^{1}$ & $18-20^{\mathrm{e}}$ & $53795 ; 53812$ \\
\hline $\begin{array}{l}\text { Geissleria kriegeri (Krasske) } \\
\text { Lange-Bertalot }\end{array}$ & $22,9^{c} / 7,9^{1}$ & $12^{\mathrm{e}}$ & 53811 \\
\hline $\begin{array}{l}\text { Geissleria aikenensis (Patrick) } \\
\text { Torgan \& Oliveira }\end{array}$ & $24,5^{\mathrm{c}} / 6,3^{1}$ & $14^{\mathrm{e}}$ & 53809 \\
\hline $\begin{array}{l}\text { Mayamaea atomus var. permitis } \\
\text { (Hustedt) Lange-Bertalot }\end{array}$ & $8,3-9,0^{\mathrm{c}} / 3,3-4,0^{1}$ & $26^{\mathrm{e}}$ & 53801 \\
\hline $\begin{array}{l}\text { Nupela praecipua } \\
\text { (Reichardt) Reichardt }\end{array}$ & $8,7-16,0^{c} / 4,0-5,5^{1}$ & & $\begin{array}{l}53795 ; 53801 ; 53809 ; 53811 ; \\
53812 ; 53819 ; 53822 ; 53826\end{array}$ \\
\hline
\end{tabular}

Nota: comprimento (c), largura (l), diâmetro (d), altura valvar (h), estrias (e), estrias dorsais (ed), estrias ventrais (ev), aréolas (a), fíbulas (f), projeções aliformes (pa), (vr) valva com rafe, (vsr) valva sem rafe. 
Tabela 2. Continuação.

Table 2. Continued.

\begin{tabular}{|c|c|c|c|}
\hline \multirow[t]{2}{*}{ Famílias/espécies } & \multicolumn{2}{|c|}{ Dados merísticos } & \multirow{2}{*}{$\begin{array}{c}\text { Número de registro } \\
\text { das amostras (UPCB) }\end{array}$} \\
\hline & $\mu \mathrm{m}$ & em $10 \mu \mathrm{m}$ & \\
\hline Nupela sp. & $13,4-15,8^{\mathrm{c}} / 4,0-4,7^{1}$ & & $53809 ; 53811$ \\
\hline \multicolumn{4}{|l|}{ PLEUROSIGMATACEAE } \\
\hline $\begin{array}{l}\text { Gyrosigma eximium } \\
\text { (Thwaites) Boyer }\end{array}$ & $67,3-76,0^{c} / 9,3-9,5^{1}$ & $18^{\mathrm{e}}$ & 53826 \\
\hline \multicolumn{4}{|l|}{ STAURONEIDACEAE } \\
\hline Stauroneis anceps Ehrenberg & $75,2-92,0^{\mathrm{c}} / 13,6-16,0^{1}$ & $16-18^{\mathrm{e}} / 18^{\mathrm{a}}$ & 53801 \\
\hline $\begin{array}{l}\text { Stauroneis gracilior } \\
\text { (Rabenhorst) Reichardt }\end{array}$ & $51,2-55,2^{\mathrm{c}} / 8,2-9,5^{1}$ & $24^{\mathrm{e}}$ & $53801 ; 53811$ \\
\hline Stauroneis gracilis Ehrenberg & $81,4-117,2^{\mathrm{c}} / 15,8-21,8^{1}$ & $16-18^{\mathrm{e}} / 16-18^{\mathrm{a}}$ & 53795 \\
\hline $\begin{array}{l}\text { Stauroneis phoenicenteron } \\
\text { (Nitzsch) Ehrenberg }\end{array}$ & $109,5-146,4^{\mathrm{c}} / 21,6-25,6^{1}$ & $16-18^{\mathrm{e}} / 14-16^{\mathrm{a}}$ & $53801 ; 53811 ; 53826$ \\
\hline Stauroneis tenera Hustedt & $16,6-26,1^{\mathrm{c}} / 3,2-4,0^{1}$ & & 53801; 53809; 53811; 53822 \\
\hline $\begin{array}{l}\text { Craticula riparia } \\
\text { (Hustedt) Lange-Bertalot }\end{array}$ & $36,4-48,0^{c} / 7,2-8,8^{1}$ & $16-18^{\mathrm{e}}$ & $53801 ; 53811$ \\
\hline $\begin{array}{l}\text { Craticula submolesta } \\
\text { (Hustedt) Lange-Bertalot }\end{array}$ & $15,8-24,0^{c} / 4,0-5,6^{1}$ & $18^{\mathrm{e}}$ & $53795 ; 53801 ; 53811$ \\
\hline \multicolumn{4}{|l|}{ CATENULACEAE } \\
\hline $\begin{array}{l}\text { Amphora copulata (Kützing) } \\
\text { Schoeman \& Archibald }\end{array}$ & $33,3^{\mathrm{c}} / 6,7^{1}$ & $14^{\mathrm{ed}, \mathrm{ev}} / 12^{\mathrm{a}}$ & 53801 \\
\hline \multicolumn{4}{|l|}{ BACILLARIACEAE } \\
\hline Nitzschia amphibia Grunow & $37,1^{\mathrm{c}} / 4,7^{1}$ & $14^{\mathrm{e}} / 12^{\mathrm{a}} / 7^{\mathrm{f}}$ & 53822 \\
\hline Nitzschia clausii Hantzsch & $28,4-43,5^{\mathrm{c}} / 3,2-4,0^{1}$ & $8-10^{f}$ & $53811 ; 53822 ; 53826$ \\
\hline Nitzschia gracilis Hantzsch & $44,2-67,9^{c} / 3,2-4,7^{1}$ & $12-14^{\mathrm{f}}$ & $53801 ; 53811 ; 53819$ \\
\hline $\begin{array}{l}\text { Nitzschia palea } \\
\text { (Kützing) Wm. Smith }\end{array}$ & $32,0-52,8^{c} / 3,2-4,7^{1}$ & $11-14^{\mathrm{f}}$ & $\begin{array}{c}53795 ; 53801 ; 53809 ; 53811 ; 53819 ; \\
5382 ; 53826\end{array}$ \\
\hline $\begin{array}{l}\text { Nitzschia perminuta } \\
\text { (Grunow) Peragallo }\end{array}$ & $15,0-22,1^{\mathrm{c}} / 2,4-3,2^{1}$ & $10-12^{\mathrm{f}}$ & $53811 ; 53826$ \\
\hline Nitzschia recta Hantzsch & $56,1-68,7^{c} / 4,0-4,7^{1}$ & $5-6^{\mathrm{f}}$ & 53795; 53809; 53822 \\
\hline $\begin{array}{l}\text { Nitzschia terrestris } \\
\text { (Petersen) Hustedt }\end{array}$ & $47,4-63,2^{\mathrm{c}} / 4,0^{1}$ & $5-7^{\mathrm{f}}$ & $53811 ; 53819$ \\
\hline \multicolumn{4}{|l|}{ SURIRELLACEAE } \\
\hline $\begin{array}{l}\text { Stenopterobia delicatissima } \\
\text { (Lewis) Van Heurck }\end{array}$ & $26,9-52,9^{c} / 4,0-7,9^{1}$ & $24^{\mathrm{e}} / 7-8^{\mathrm{pa}}$ & $53795 ; 53801 ; 53811 ; 53826$ \\
\hline $\begin{array}{l}\text { Stenopterobia planctonica } \\
\text { Metzeltin \& Lange-Bertalot }\end{array}$ & $87,2-164,8^{c} / 3,2-4,8^{1}$ & $6-8^{\mathrm{pa}}$ & $53801 ; 53811 ; 53826$ \\
\hline Surirella angusta Kützing & $32,4-39,5^{c} / 7,1-7,9^{1}$ & $6-8^{\mathrm{pa}}$ & $53795 ; 53809 ; 53822$ \\
\hline Surirella elegans Ehrenberg & $77,3^{c} / 23,6^{1}$ & $3^{\text {pa }}$ & 53822 \\
\hline Surirella guatimalensis Ehrenberg & $142,4^{\mathrm{c}} / 57,6^{1}$ & $3^{\mathrm{pa}}$ & 53801 \\
\hline $\begin{array}{l}\text { Surirella linearis } \\
\text { Smith var. linearis }\end{array}$ & $104,0-107,4^{\mathrm{c}} / 29,2-3,6^{1}$ & $2^{\mathrm{pa}}$ & $53801 ; 53811$ \\
\hline $\begin{array}{l}\text { Surirella linearis } \\
\text { var. constricta Grunow }\end{array}$ & $139,0-156,0^{c} / 18-20^{1}$ & $2^{\mathrm{pa}}$ & $53795 ; 53822$ \\
\hline $\begin{array}{l}\text { Surirella lineares } \\
\text { var. helvetica (Brun.) Meister }\end{array}$ & $41,0-52,0^{\mathrm{c}} / 13,0-15,8^{1}$ & $3^{\mathrm{pa}}$ & 53822 \\
\hline $\begin{array}{l}\text { Surirella nervosa } \\
\text { (A. Schmidt) Mayer }\end{array}$ & $63,3-70,0^{c} / 24,7-26,6^{1}$ & $3-4^{\mathrm{pa}}$ & 53801 \\
\hline $\begin{array}{l}\text { Surirella splendida } \\
\text { (Ehrenberg) Kützing }\end{array}$ & $94,4-96,3^{\mathrm{c}} / 30,1-32,8^{1}$ & $2^{\mathrm{pa}}$ & 53801 \\
\hline $\begin{array}{l}\text { Surirella stalagma } \\
\text { Hohn \& Hellermann }\end{array}$ & $14,7^{\mathfrak{c}} / 6,7^{1}$ & $6^{\mathrm{pa}}$ & 53811 \\
\hline Surirella tenuissima Hustedt & $26,6-29,3^{\mathrm{c}} / 7,2-8,6^{1}$ & $3-4^{\mathrm{pa}}$ & $53801 ; 53809 ; 53811$ \\
\hline
\end{tabular}

Nota: comprimento (c), largura (l), diâmetro (d), altura valvar (h), estrias (e), estrias dorsais (ed), estrias ventrais (ev), aréolas (a), fíbulas (f), projeções aliformes (pa), (vr) valva com rafe, (vsr) valva sem rafe. 
Os exemplares observados assemelharam-se à Eunotia donatoi Metzeltin \& Lange-Bertalot, porém esta espécie apresenta valvas levemente mais largas $(7,3-8,0 \mu \mathrm{m})$ que a do material analisado (Metzeltin \& Lange-Bertalot 2007). Semelhança também foi encontrada com o material registrado como Eunotia (? nov.) spec. Nr. 58/5-10 por Metzeltin \& Lange-Bertalot (1998, pl. 58, figs 5-10), porém os autores não realizaram denominação infragenérica para o táxon.

Eunotia aff. siolii Hustedt, Ber. Deustch. Bot. Ges., n. 65, p. 133-144, pl. 143, f. 13-15, 1952. (Figuras 6-8)

Valvas com margem dorsal convexa; margem ventral reta a levemente côncava; extremidades atenuado-arredondadas, levemente destacadas do corpo valvar; nódulos terminais nas extremidades, conspícuos; estrias paralelas na região mediana da valva; aréolas inconspícuas. Comprimento: 29,3-39,9 $\mu \mathrm{m}$; largura: 5,5-5,9 $\mu \mathrm{m}$; estrias: $8-9$ em $10 \mu \mathrm{m}$.

Os exemplares encontrados assemelharam-se aos registrados por Metzeltin \& Lange-Bertalot (2007, pl. 102, figs 35-42) como Eunotia (? nov.) spec. cf. siolii Hustedt, no que se refere ao contorno valvar e padrão de estriação. No entanto, a população analisada apresentou variação métrica pouco maior. Comparando-se os exemplares estudados com Eunotia siolii Hustetd, nota-se que esta possui extremidades menos destacadas do corpo valvar e frústulas com menores dimensões (Krammer \& Lange-Bertalot 1991a).

Outra espécie semelhante é Eunotia odebrechtiana Metzeltin \& Lange-Bertalot, porém, segundo as ilustrações apresentadas por Metzeltin \& Lange-Bertalot (1998), esta espécie apresenta estrias encurtadas, mostrando-se aparentemente bifurcadas próximas a margem dorsal da valva, o que não ocorre na espécie em questão.

Encyonema neogracile var. tenuipunctata Krammer, Biblioth. Diatomol. 36: 143, pl. 83, Figuras 4-7, pl. 85, Figuras 1-6, 11, 12, pl. 90, Figuras 3, 4, 1997a. (Figuras 11-14)

Valvas dorsiventrais; margem dorsal convexa; margem ventral reta, por vezes apresentando intumescimento na região mediana; extremidades atenuado-arredondadas; esterno da rafe linear, estreito; área central reduzida; estigmóide presente na porção mediana dorsal; rafe filiforme, terminações distais fletidas ventralmente, terminações proximais fletidas dorsalmente; estrias dorsais e ventrais levemente radiadas a convergentes em direção às extremidades valvares. Comprimento: 36,0-56,8 $\mu \mathrm{m}$; largura: 4,8-9,2 $\mu \mathrm{m}$; estrias dorsais e ventrais: $12-14 \mathrm{em} 10 \mu \mathrm{m}$; aréolas: $32 \mathrm{em} 10 \mu \mathrm{m}$.

Segundo Krammer (1997a), Encyonema neogracile var. tenuipunctata difere da variedade típica por apresentar uma maior densidade de aréolas, ou seja, a variedade típica apresenta menos de 28 aréolas em $10 \mu \mathrm{m}$, já a var. tenuipunctata apresenta de 28 a 32 aréolas em $10 \mu \mathrm{m}$.

Encyonopsis kaingensis (Vyverman) Krammer, Bibith. Diatomol. 37(2): 139, pl. 140, Figuras17-19, 1997.

Basiônimo: Cymbella kaingensis Vyverman, Diat. Res. 3(2): 259, 262, figs 1-6, 12-15, 1988. (Figuras 15-16)

Valvas lineares, levemente assimétricas; ambas as margens convexas; extremidades subrostradas; esterno da rafe lanceolado; área central lanceolada; estigmóide não visualizado; rafe arqueada, terminações distais fletidas ventralmente, terminações proximais fletidas dorsalmente; estrias dorsais e ventrais radiadas, convergentes nas extremidades valvares; aréolas inconspícuas. Comprimento: 26,1-40,6 $\mu \mathrm{m}$; largura: 6,3-6,8 $\mu \mathrm{m}$; estrias dorsais e ventrais: $13-15$ em $10 \mu \mathrm{m}$.

O material analisado concordou com o descrito e ilustrado por Vyverman (1991) e Krammer (1997b), exceto por apresentar valvas pouco menores e mais largas que as descritas na literatura (29-40 $\mu \mathrm{m}$ de comprimento e 5,1-6,1 $\mu \mathrm{m}$ de largura). Vyverman (1991) comenta ainda que um estigmóide dorsal geralmente está presente e que este não é visível em microscopia óptica convencional. Nos poucos exemplares estudados não foi possível observar o estigmóide.

Encyonopsis sp. (Figuras 17-20)
Valvas lanceoladas, levemente assimétricas; ambas as margens convexas; extremidades capitadas a subrostradas, esterno da rafe lanceolado; área central lanceolada; estigmóide ausente; rafe filiforme, terminações distais fletidas ventralmente, terminações proximais fletidas dorsalmente; estrias dorsais e ventrais radiadas, levemente convergentes nas extremidades valvares; aréolas inconspícuas. Comprimento: 15,8-25,6 $\mu \mathrm{m}$; largura: 5,5-6,4 $\mu \mathrm{m}$; estrias dorsais: 10-12 em $10 \mu \mathrm{m}$; estrias ventrais: 9-10 em $10 \mu \mathrm{m}$; razão comprimento/largura de 2,8-4,0 $\mu \mathrm{m}$.

A população encontrada apresentou semelhanças com Encyonopsis difficiliformis Krammer e Encyonopsis difficilis (Krasske) Krammer. As duas espécies podem ser facilmente confundidas, porém Krammer (1997b) as separa comentando que E. difficiliformis apresenta valvas mais largas $(6,7-7,8 \mu \mathrm{m})$ e razão comprimento/largura menor que 4,7 $\mu \mathrm{m}$. Já, Encyonopsis difficilis apresenta valvas mais estreitas (4,6-6,2 $\mu \mathrm{m})$ e razão comprimento/largura menor que 5,3 $\mu \mathrm{m}$. O material analisado, no entanto, apresentou medidas intermediárias e diferiu destas espécies pela forma mais capitada das extremidades e pela forma mais lanceolada das valvas.

Outra espécie similar é Encyonopsis subcapitata Krammer, mas esta possui esterno da rafe mais estreito e valvas de maiores dimensões (26-41 $\mu \mathrm{m}$ de comprimento, $8-9 \mu \mathrm{m}$ de largura, 8 estrias em $10 \mu \mathrm{m}$ e razão comprimento/largura $=4,6 \mu \mathrm{m}$ ) que as analisadas neste estudo (Krammer 1997b). Há, portanto, necessidade de estudos mais detalhados dos exemplares encontrados para se averiguar a possibilidade de tratar-se de uma nova espécie para a ciência.

\section{Achnanthidium sp. (Figuras 21-24)}

Valvas elípticas a elíptico-lanceoladas; extremidades amplamente subrostradas. Valva com rafe: esterno da rafe linear, estreito; área central reduzida; rafe reta; estrias radiadas, levemente mais espaçadas na região mediana da valva; aréolas inconspícuas. Valva sem rafe: esterno linear, estreito; área central ausente; estrias radiadas, mais espaçadas na região mediana da valva; aréolas inconspícuas. Comprimento: 7,9-11,1 $\mu \mathrm{m}$; largura: 3,2-4,0 $\mu \mathrm{m}$; estrias na valva rafídea: 18-20 em $10 \mu \mathrm{m}$; estrias na valva arrafídea: 18-24.

Achnanthidium sp. é semelhante à A. eutrophilum (LangeBertalot) Lange-Bertalot e A. modestiforme (Lange-Bertalot) Van de Vijver com relação à presença de uma estria mediana mais afastada que as demais na valva rafídea e esterno lanceolado na valva arrafídea. No entanto, as extremidades valvares de A. eutrophilum são atenuadoarredondadas e as de $A$. modestiforme subcapitadas (Lange-Bertalot \& Krammer 1989, Morales et al. 2007, Ponader \& Potapova 2007, Potapova \& Hamilton 2007).

Diadesmis implicata Moser, Lange-Bertalot \& Metzeltin, Biblioth. Diatomol. 38: 145, pl. 27, figs 6-8, 11, 1998. (Figuras 25-26)

Valvas lineares, levemente intumescidas na região mediana; extremidades arredondadas; esterno da rafe linear; área central linear atingindo as margens valvares, rafe filiforme; estrias inconspícuas. Comprimento: 8,3-11,9 $\mu \mathrm{m}$; largura: 2,7-3,2 $\mu \mathrm{m}$.

Quando comparada a Diadesmis contenta (Grunow) Mann, espécie mais comumente encontrada, $D$. implicata distingue-se pelo contorno valvar mais alargado na região central da valva e pela área central arredondada limitada por estrias medianas encurtadas (Moser et al. 1998).

Diadesmis pseudolangebertalotii Metzeltin, Lange-Bertalot \& García-Rodríguez, Iconog. Diatomol. 15: 45, pl.56, Figuras 11-24, 2005. (Figuras 27-29)

Valvas lineares, levemente constritas na região mediana; extremidades subrostradas; esterno da rafe linear, estreito; área central linear limitada pelo encurtamento das estrias medianas; rafe filiforme; estrias inconspícuas. Comprimento: 10,1-14,3 $\mu \mathrm{m}$; largura: 3,3-3,5 $\mu \mathrm{m}$.

A espécie diferencia-se de $D$. contenta pelo fato desta última apresentar extremidades largamente arredondadas, área central linear expandida até as margens valvares e região mediana sem contrição (Metzeltin et al. 2005). 
Neidium improvisum Metzeltin \& Lange-Bertalot, Iconogr. Diatomol. 11: 42, pl. 50, figs 16-18, pl. 54, figs 3-5, 2002. (Figura 30)

Valvas elíptico-lanceoladas; extremidades sub-rostradas; esterno da rafe linear, estreito; área central expandida lateralmente; rafe filiforme, extremidades proximais fletidas para lados opostos; estrias delicadas, retas, linha hialina longitudinal não visualizada. Comprimento: 29,237,1 $\mu \mathrm{m}$; largura: 7,5-8,7 $\mu \mathrm{m}$; estrias: $26 \mathrm{em} 10 \mu \mathrm{m}$.

Neidium hercynicum f. subrostratum Wallace difere de Neidium improvisum, principalmente, por apresentar área central diagonalmente expandida e estrias oblíquas (Patrick \& Reimer 1966).

Sellaphora capitata Mann \& McDonald, Phycol. 43(4): 477, figs 4j-1, figs 38-42, 2004. (Figuras 31-35)

Valvas linear-elípticas; extremidades subcapitadas; esterno da rafe linear, estreito; área central expandida lateralmente, limitada pelo encurtamento das estrias medianas; rafe filiforme, extremidades proximais sutilmente fletidas para um dos lados; estrias curvoradiadas, delicadas, mais espaçadas e retas na região mediana da valva; aréolas inconspícuas. Comprimento: 23,2-28,0 $\mu \mathrm{m}$; largura: 7,1-7,9 $\mu \mathrm{m}$; estrias: 17-21 em $10 \mu \mathrm{m}$.

De acordo com Mann et al. (2004), Sellaphora capitata difere de Sellaphora pupula (Kützing) Mereschkowsky por apresentar extremidades subcapitadas, rafe sinuosa, menor densidade de estrias (16-22 em $10 \mu \mathrm{m})$, sendo estas fortemente radiadas em toda a superfície valvar. Por sua vez, Sellaphora pupula apresenta extremidades rostradas, rafe filiforme, maior densidade de estrias (21-26 em $10 \mu \mathrm{m})$, além de estrias radiadas na porção mediana da valva, tornando-se convergentes em direção às extremidades.

Outra espécie semelhante a $S$. capitata é $S$. densistriata (LangeBertalot \& Metzeltin) Lange-Bertalot \& Metzeltin que se diferencia, principalmente, pela maior densidade de estrias na valva (25-28 em $\mu$ ) (Metzeltin \& Lange-Bertalot 2002).

\section{Pinnularia sp.1 (Figura 36)}

Valvas lineares; extremidades rostrado-cuneado; esterno da rafe lanceolado; área central ampla, alcançando as margens valvares; rafe filiforme, extremidades proximais dilatadas, levemente fletidas para o mesmo lado; estrias alveoladas, radiadas na região mediana da valva, convergentes em direção às extremidades. Comprimento: 43,4-57,6 $\mu \mathrm{m}$; largura: 8,0-9,3 $\mu \mathrm{m}$; estrias: 10-12 em $10 \mu \mathrm{m}$.

Os exemplares encontrados apresentaram semelhanças com os registrados por Metzeltin et al. (2005, pl. 170, figs 1-8). Contudo, os autores não realizaram a determinação taxonômica da espécie, citando-a como Pinnularia (?nov.) spec. Difere de Pinnularia certa por esta apresentar estrias mais alongadas e extremidades valvares rostrado-arredondadas e menos destacadas do corpo da valva (Metzeltin \& Lange-Bertalot 1998). Assemelha-se também à Pinnularia gibba Ehrenberg, porém esta espécie apresenta extremidades amplamente rostrado-arredondadas e valvas com maiores dimensões $(60-110 \mu \mathrm{m}$ de comprimento, $10-13,5 \mu \mathrm{m}$ de largura) e menor densidade de estrias (8-11 em $10 \mu \mathrm{m})($ Krammer 2000).

\section{Pinnularia sp.2 (Figuras 37-38)}

Valvas linear-lanceoladas; extremidades subcapitadas; esterno da rafe lanceolado, área central arredondada, mais expandida para um dos lados da valva; rafe filiforme, extremidades proximais dilatadas, fletidas para o mesmo lado; estrias alveoladas, radiadas, convergentes em direção às extremidades. Comprimento: $36,0-56,8 \mu \mathrm{m}$; largura: 5,6-7,5 $\mu \mathrm{m}$; estrias: 10-12 em $10 \mu \mathrm{m}$.

A população analisada apresentou semelhança com Pinnularia subcapitata Gregory, mas esta última espécie possui valvas mais delgadas (4-6,8 $\mu \mathrm{m}$ de largura) e extremidades mais destacadas do corpo valvar (Krammer 2000).

\section{Pinnularia sp.3 (Figura 39)}

Valva linear; extremidades amplamente rostrado-arredondadas; esterno da rafe lanceolado, amplo; área central lateralmente expandida, alcançando as margens valvares; rafe filiforme, extremidades proximais dilatadas, fletidas para o mesmo lado; estrias alveoladas, fortemente radiadas, convergentes em direção às extremidades. Comprimento: 19,0 $\mu \mathrm{m}$; largura: 4,7 $\mu \mathrm{m}$; estrias: $14 \mathrm{em} 10 \mu \mathrm{m}$.

O espécime observado assemelha-se ao ilustrado por Metzeltin \& Lange-Bertalot (1998, pl. 185, Figura 7), tratando-se possivelmente de uma nova espécie, porém os autores não apresentam denominação infragenérica para este exemplar, como também não fornecem informações em relação ao seu habitat. Alguma semelhança pode ser constatada com P. metzeltinii Krammer, mas esta possui valvas pouco mais largas $(5,2-5,7 \mu \mathrm{m}$ de largura) e estrias mais alongadas em direção ao esterno da rafe (Krammer 2000).

Eolimna lepidula (Manguin) Metzeltin \& Lange-Bertalot, Iconogr. Diatomol. 18: 82, pl. 140, figs. 28-30, 2007.

Basiônimo: Navicula lepidula Manguin in Bourrelly \& Manguin, Centr. Nat. Rech. Sci., p. 70; pl. 4, Figuras 88 a-b, 1952. (Figuras 40-41)

Valvas elíptico-lanceoladas; extremidades arredondadas; esterno da rafe linear, estreito; área central lateralmente expandida, limitada pelo encurtamento de quatro estrias medianas; rafe filiforme, extremidades proximais retas; estrias radiadas em toda a extensão valvar; aréolas inconspícuas. Comprimento: 11,0-11,9 $\mu \mathrm{m}$; largura: $4,7 \mu \mathrm{m}$; estrias: $18 \mathrm{em} 10 \mu \mathrm{m}$.

Exemplares semelhantes à Eolimna lepidula foram ilustrados por Lange-Bertalot et al. (1996) como Navicula pseudofossalis Krasske. No entanto, os indivíduos analisados neste estudo apresentaram valvas maiores e com maior densidade de estrias que as descritas para o material tipo de $N$. pseudofossalis ( $9 \mu \mathrm{m}$ de comprimento, 4,5 $\mu \mathrm{m}$ de largura e 28 estrias em $10 \mu \mathrm{m}$ ). Além disso, quando se observa a ilustração original de Krasske, nota-se que N. pseudofossalis possui área central pequena, sendo limitada por três estrias medianas. Já E. lepidula tem área central amplamente expandida, limitada por estrias medianas (Metzeltin \& Lange-Bertalot 2007).

\section{Nupela sp. (Figura 42-44)}

Valvas linear-lanceoladas; extremidades subrostradas; esterno da rafe linear, estreito; área central arredondada; rafe filiforme, extremidades proximais retas, mais encurtadas na região mediana em uma das valvas; estrias inconspícuas. Comprimento: 13,4-15,8 $\mu \mathrm{m}$; largura: 4,0-4,7 $\mu \mathrm{m}$.

Rumrich et al. (2000) ilustraram espécimes para o Equador semelhantes (pl. 32, figs 12-13) aos encontrados no presente estudo, porém não realizaram a determinação infragenérica do táxon. Pelas ilustrações apresentadas pode-se perceber que a espécie apresenta os ramos da rafe mais encurtados na região mediana em uma das valvas, acarretando em uma ampla área central refringente.

Stauroneis tenera Hustedt, Arch. Hydrobiol. 1: 225, pl. 16, Figuras 19-21, 1937. (Figura 45)

Valvas linear-lanceoladas; extremidades apiculadas; pseudosepto presente; esterno da rafe linear, estreito; estauro linear, alcançando as margens da valva; rafe filiforme, extremidades proximais retas; estrias inconspícuas. Comprimento: 16,6-26,1 $\mu \mathrm{m}$; largura: 3,2-4,0 $\mu \mathrm{m}$.

Este táxon é semelhante à Stauroneis prominula Hustedt, mas difere por este apresentar margens valvares lineares a côncava, extremidades rostradas e estauro elíptico. Outra espécie similar é Stauroneis smithii Grunow, porém esta se caracteriza pelas margens valvares trionduladas, sendo a ondulação mediana mais proeminente do que as demais (Hustedt 1927-1930).

Stenopterobia planctonica Metzeltin \& Lange-Bertalot, Iconogr. Diatomol. 5: 221, pl. 219, Figura 3, pl. 210, Figura 4, 1998. (Figura 46)

Valvas sigmóides; extremidades atenuado-arredondadas; esterno linear, estreito, de difícil visualização; projeções aliformes delicadas, paralelas na região mediana da valva e radiadas nas extremidades valvares; estrias inconspícuas. Comprimento: 87,2-164,8 $\mu \mathrm{m}$; largura: 3,2-4,8 $\mu \mathrm{m}$; projeções aliformes: $6-8 \mathrm{em} 10 \mu \mathrm{m}$.

Além de $S$. planctonica, outras espécies de Stenopterobia apresentam contorno valvar sigmóide, tais como $S$. pelagica Hustedt, 

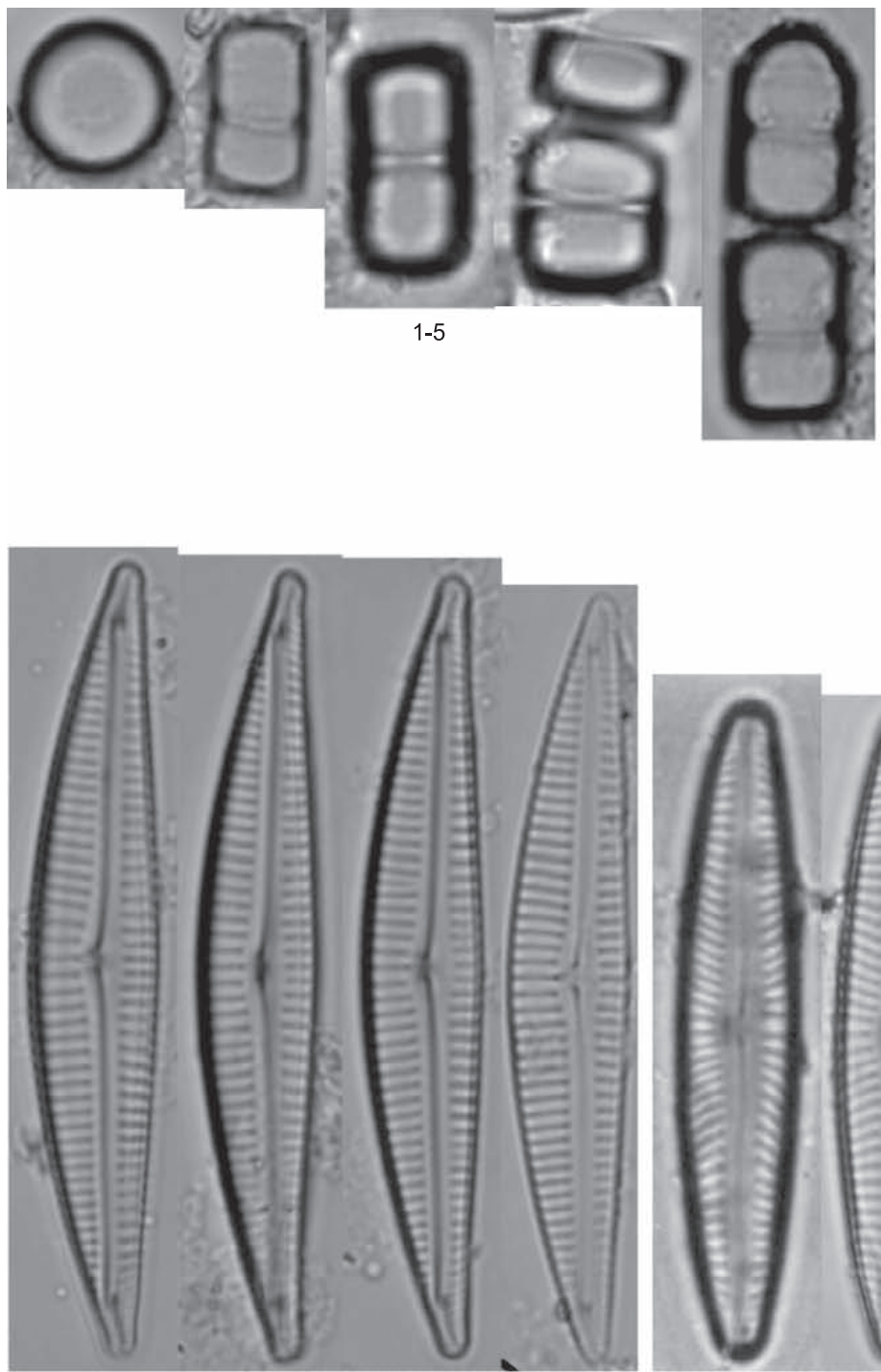

$11-14$

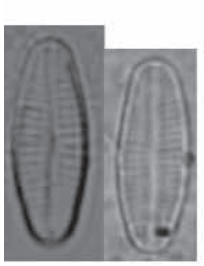

21-22

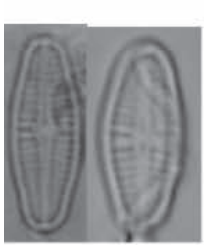

$23-24$

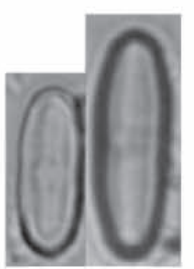

$25-26$

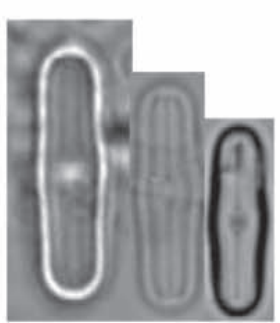

$27-29$
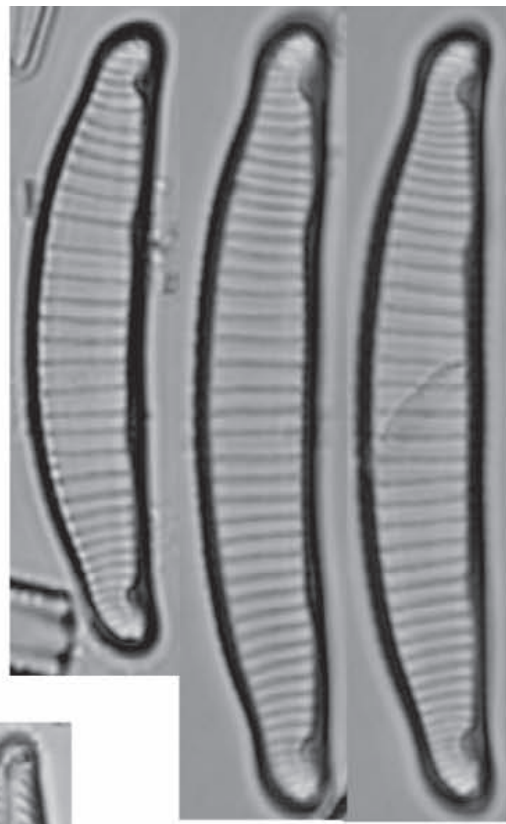

6-8
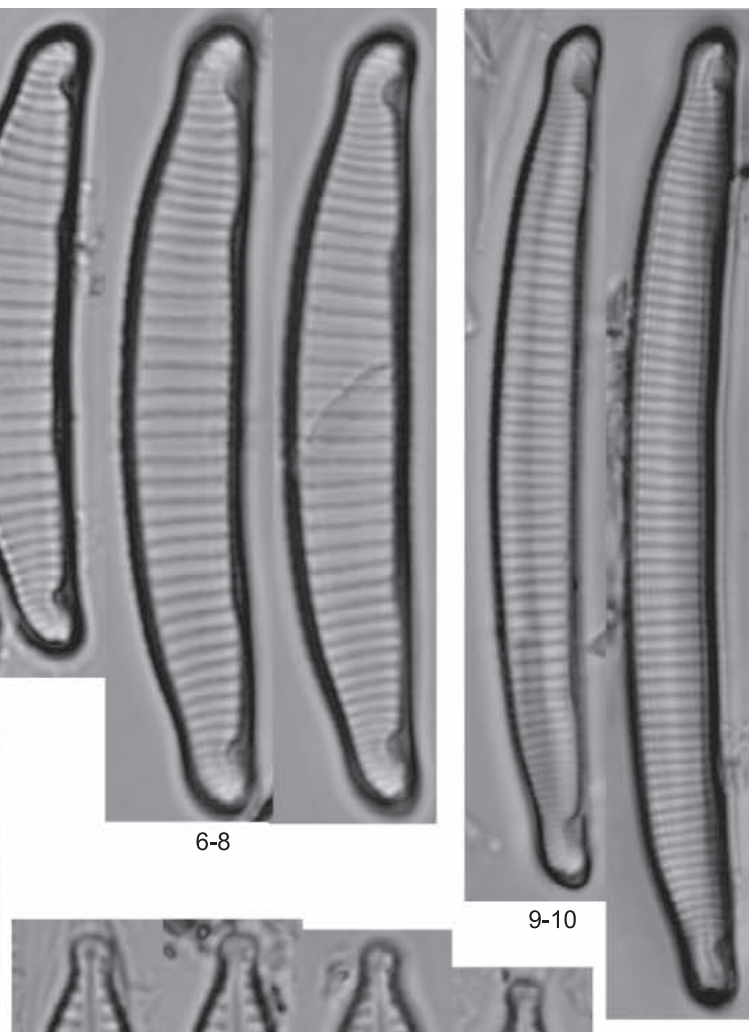

Figuras 1-35. 1-5. Melosira sp., 6-8. Eunotia aff. siolli, 9-10. Eunotia aff. donatoi, 11-14. Encyonema neogracile var. tenuipunctata, 15-16. Encyonopsis kaigensis, 17-20. Encyonopsis sp. 21-24. Achnanthidium sp., 25-26. Diadesmis implicata, 27-29. Diadesmis langebertalotii, 30. Neidium improvisum, 31-35. Sellaphora capitata. Escala: $10 \mu \mathrm{m}$.

Figures 1-35. 1-5. Melosira sp., 6-8. Eunotia aff. siolli, 9-10. Eunotia aff. donatoi, 11-14. Encyonema neogracile var. tenuipunctata, 15-16. Encyonopsis kaigensis, 17-20. Encyonopsis sp., 21-24. Achnanthidium sp., 25-26. Diadesmis implicata, 27-29. Diadesmis langebertalotii, 30. Neidium improvisum, 31-35. Sellaphora capitata. Scale: $10 \mu \mathrm{m}$. 
S. curvula (W. Smith) Krammer, S. anceps (Lewis) Brébisson e S. densestriata (Hustedt) Krammer. Apesar da semelhança na forma, S. pelagica e $S$. curvula possuem valvas mais largas (6-7 $\mu \mathrm{m}$ e $6-9 \mu \mathrm{m}$ de largura, respectivamente), $S$. anceps apresenta extremidades mais largas e valvas com maiores dimensões (140-320 $\mu \mathrm{m}$ de comprimento e 9-12 $\mu \mathrm{m}$ de largura) e $S$. densestriata mostra valvas levemente mais largas (4,5-7 $\mu \mathrm{m})$ e menos sigmóides (Huber-Pestalozzi 1942, Krammer \& Lange-Bertalot 1988).
Apenas um exemplar de Pinnularia sp.4 foi encontrado nas amostras analisadas, fato que dificultou sua determinação infragenérica. Indivíduo similar a este foi registrado por Brassac \& Ludwig (2006) quando do estudo das Pinnularia Ehrenberg e Caloneis Cleve da bacia do rio Iguaçu, Paraná. O único exemplar encontrado pelos autores apresentou valva com maior dimensão $(61,5 \mu \mathrm{m}$ de comprimento, $8,4 \mu \mathrm{m}$ de largura, 11 estrias em $10 \mu \mathrm{m}$ ) que o registrado neste estudo (44,2 $\mu \mathrm{m}$ de comprimento, $8,1 \mu \mathrm{m}$ de largura e 10 estrias em $10 \mu \mathrm{m})$.

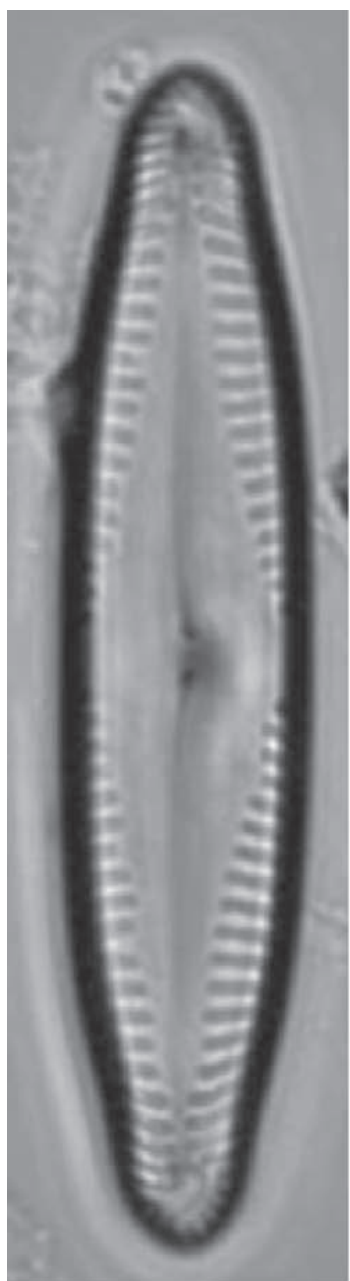

36

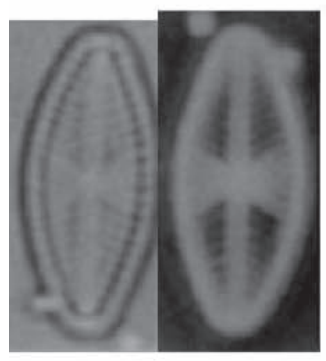

$40-41$

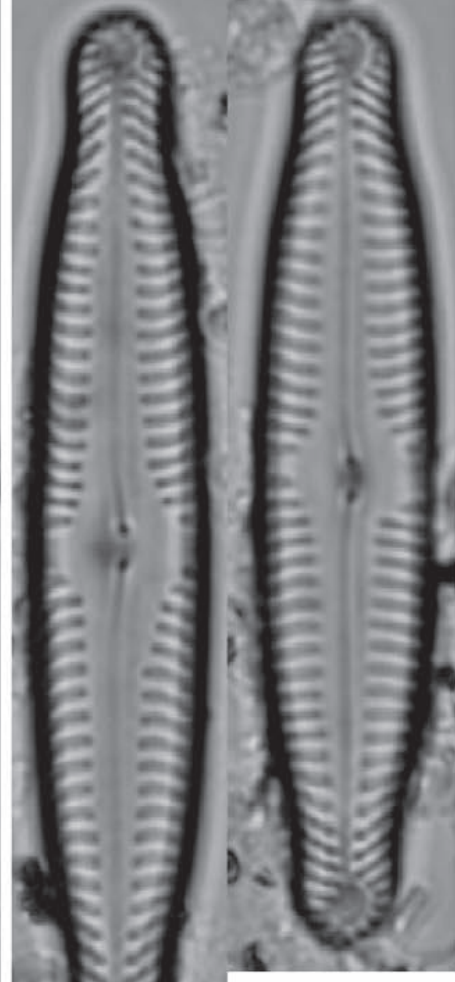

$37-38$

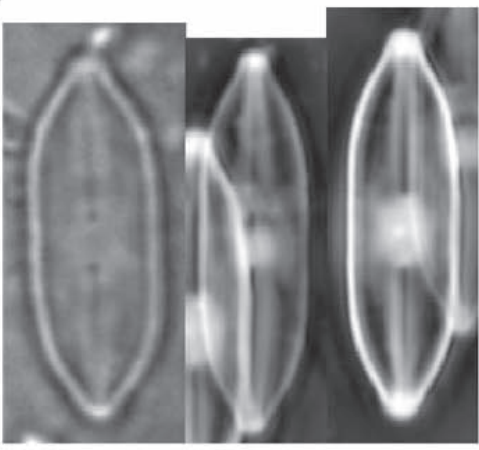

$42-44$

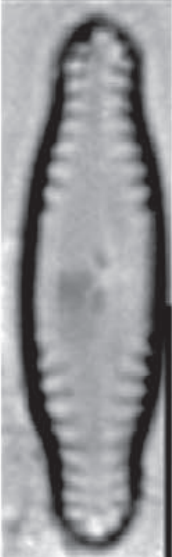

39

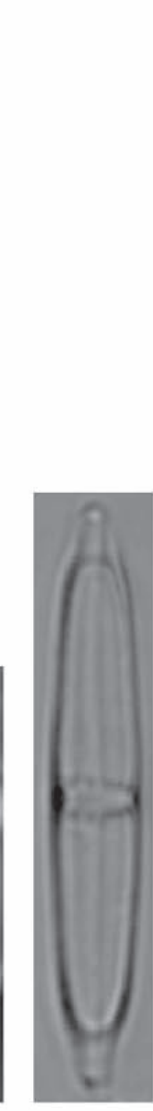

45

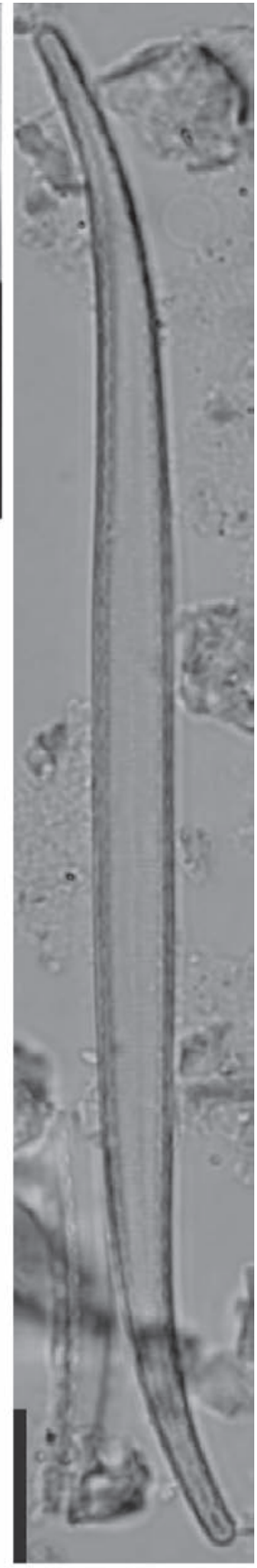

46

$10 \mu \mathrm{m}$

Figuras 36-46. 36. Pinnularia sp.1,. 37-38. Pinnularia sp.2, 39. Pinnularia sp.3, 40-41. Eolimna lepidula, 42-44. Nupela sp., 45. Stauroneis tenera, 46. Stenopterobia planctonica. Escala: $10 \mu \mathrm{m}$.

Figures 36-46. 36. Pinnularia sp.1, 37-38. Pinnularia sp.2, 39. Pinnularia sp.3, 40-41. Eolimna lepidula, 42-44. Nupela sp., 45. Stauroneis tenera, 46. Stenopterobia planctonica. Scale: $10 \mu \mathrm{m}$. 


\section{Agradecimentos}

A CAPES pela concessão de bolsa de mestrado à Eloési dos Santos e de doutorado à Priscila Tremarin. E ao CNPq pela bolsa de produtividade científica à Dr. Thelma Ludwig.

\section{Referências Bibliográficas}

BARBER, H.G. \& HARWORTH, E.Y. 1981. A Guide to the Morphology of the Diatom Frustule. Freshwater Biological Association, Cumbria, v.44, p.1-112.

BERTOLLI, L.M., TREMARIN, P.I. \& LUDWIG, T.A.V. 2010. Diatomáceas perifíticas em Polygonum hydropiperoides Michaux, reservatório do Passaúna, Região Metropolitana de Curitiba, Paraná, Brasil. Acta Bot. Bras. 24(4): no prelo.

BRASSAC, N.M. \& LUDWIG, T.A.V. 2006. Diatomáceas da Bacia do rio Iguaçu, Paraná, Brasil: Pinnularia e Caloneis. Hoehnea 33: 127-142.

BURKHOLDER, J.M. 1996. Interactions of benthic algae with their substrata. In Algal Ecology: Freshwater Benthic Ecosystems (R.J. Stevenson, M.L. Bothwell \& L. Lowe, eds.). Academic Press, San Diego, Section 2: Factors affecting benthic algae, ch. 9, p. 253-297, (Aquatic ecology series).

CATTANEO, A. \& KALFF, J. 1979. Primary production of algae growing on natural and artificial aquactic plants: a study of interactions between epiphytes and their substrate. Limnol. Oceanogr. 24:1031-1037. http:// dx.doi.org/10.4319/lo.1979.24.6.1031

ESTEVES, F.A. 1988. Fundamentos de Limnologia. Ed. Interciência/FINEP, Rio de Janeiro.

FARIA, D.M., TREMARIN, P.I. \& LUDWIG, T.A.V. 2010. Diatomáceas perifíticas da represa Itaqui, São José dos Pinhais, Paraná: Fragilariales, Eunotiales, Achnanthales e Gomphonema Ehrenberg. Biota Neotrop. 10(3): http://www.biotaneotropica.org.br/v10n3/pt/abstract?inventory +bn04110032010.

FERRARI, F. \& LUDWIG, T.A.V. 2007. Coscinodiscophyceae, Fragilariophyceae e Bacillariophyceae (Achnanthales) dos rios Ivaí, São João e dos Patos, bacia hidrográfico do rio Ivaí, município de Prudentópolis, PR, Brasil. Acta Bot. Bras. 21(2):421-441. http://dx.doi. org/10.1590/S0102-33062007000200016

HUBER-PESTALOZZI, G. 1942. Das Phytoplankton des Süsswassers Systematik und Biologie (Diatomeen). In Die Binnengewässer (A. Thienemann, ed.). E. Schweizerbartsche Verlagsbuchhandlung, Stuttgart, v.16, part 2, p.1- 549 .

HUSTEDT, F. 1927. Die Kieselalgen. In Kryptogamen-Flora (L. Rabenhorst, ed.). Akademische Verlagsgesellschaft, Leipzig, v. 7, pars 1, p.1-920.

KRAMMER, K. 1997a. Die cymbelloiden Diatomeen: eine monographie der weltweit bekannten taxa. I Allgemeines und Encyonema Part. Biblioth. Diatomol. 36:1-382.

KRAMMER, K. 1997b. Die cymbelloiden Diatomeen: eine monographie der weltweit bekannten taxa. II Encyonema Part., Encyonopsis and Cymbellopsis. Biblioth. Diatomol. 37:1-469.

KRAMMER, K. \& LANGE-BERTALOT, H. 1988. Bacillariophyceae: Bacillariaceae, Epithemiaceae, Surirellaceae. In Sübwasserflora von Mitteleuropa (H. Ettl, J. Gerloff, H. Heynig, \& D. Mollenhauer, eds.). Band 2/2. Gustav Fisher Verlag, Jena, p. 1-596.

KRAMMER, K. 2000. The genus Pinnularia. Diatoms of Europe 1:1-703.

KRAMMER, K. \& LANGE-BERTALOT, H. 1991a. Bacillariophyceae: Centrales, Fragilariaceae, Eunotiaceae. In Sübwasserflora von Mitteleuropa (H. Ettl, J. Gerloff, H. Heynig, \& D. Mollenhauer, eds.). Band 2-3. Gustav Fischer Verlag, Stuttgart, Jena, p.1-576.
LANDUCCI, M. \& LUDWIG, T.A.V. 2005. Diatomáceas de rios da bacia hidrigráfica Litorânea, PR, Brasil: Coscinodiscophyceae e Feagilariophyceae. Acta Bot. Bras. 19(2):345-357. http://dx.doi. org/10.1590/S0102-33062005000200018

LANGE-BERTALOT, H. \& KRAMMER, K. 1989. Achnanthes, eine Monographie der Gattung. Biblioth. Diatomol. 18:1-393.

LANGE-BERTALOT, H., KÜLBS, K., LAUSER, T., NÖRPEL-SHEMPP, M. \& WILLMANN, M. 1996. Diatom Taxa introduced by George Krasske - documentation and revision. Iconogr. Diatomol. 3:1-358.

LEANDRINI, J.A., MOREIRA-FILHO, H. \& RODRIGUES, L. 2002. Espécies perifíticas de Navicula Bory de dois sistemas lóticos do município de Maringá, estado do Paraná, Brasil. Hoehnea 29(1):49-56.

LUDWIG, T.A.V., BIGUNAS, P.I.T., NEIVA, T.F., COQUEMALA, V. \& PICCININI, C. 2005. Diatomáceas (Ochrophyta) dos lagos do Jardim Botânico. Rer. Mus. Nac. Rio de Janeiro, série livros 10:301-323.

MANN, D.G., MACDONALD, S.M., BAYER, M.M., DROOP, S.J.M., CHEPURNOV, V.A., LOKE, R.E., CIOBANU, A. \& DU BUF, J.M.H. 2004. The Sellaphora pupula species complex (Bacillariophyceae): morphometric analysis, ultrastructure and mating data provide evidence for five new species. Phycol. 43(4):459-482. http://dx.doi.org/10.2216/ i0031-8884-43-4-459.1

METZELTIN, D. \& LANGE-BERTALOT, H. 1998. Tropical Diatoms of South America I. About 700 predominantly rarely known or new taxa representative of the neotropical flora. Iconogr. Diatomol. 5:1-220.

METZELTIN, D. \& LANGE-BERTALOT, H. 2002. Diatoms from the Island Continent Madagascar. Iconogr. Diatomol. 11:1-286.

METZELTIN, D. \& LANGE-BERTALOT, H. 2007. Tropical Diatoms of South America II. Special remarks on biogeographic disjunction. Iconogr. Diatomol. 18:1-876.

METZELTIN, D., LANGE-BERTALOT, H. \& GARCÍA-RODRÍGUEZ, F. 2005. Diatoms of Uruguay. Iconogr. Diatomol. 15:1-736.

MORALES, E.A., VIS, M.L., FERNÁNDEZ, E. \& KOCIOLEK, J.P. 2007. Epilithic diatoms (Bacillariophyta) from cloud forest and alpine streams in Bolivia, South America II: A preliminary report on the diatoms from Sorata, Department of La Paz. Rev. Acta Nova 3(4):680-696.

MOREIRA-FILHO, H. \& VALENTE-MOREIRA, I.M. 1981. Avaliação taxonômica e ecológica das diatomáceas (Bacillariophyceae) epífitas em algas pluricelulares obtidas nos litorais dos Estados do Paraná, Santa Catarina e São Paulo. Bol. Mus. Bot. Mun. 47:1-17.

MOSER, G., LANGE-BERTALOT, H. \& METZELTIN, D. 1998. Insel der Endemiten - Geobotanisches phenomen neukaledonien. Biblioth. Diatomol. 38:1-464.

PATRICK, R. \& REIMER, C.W. 1966. The diatoms of United States. Vol.1 - Fragilariaceae, Eunotiaceae, Achnanthaceae, Naviculaceae. Acad. Nat. Sci. Philadel. Monogr.13:1-688.

POMPÊO, M.L.M. \& MOSCHINI-CARLOS, V. 2003. Macrófitas aquáticas e perifíton - aspectos ecológicos e metodológicos. Rima, São Carlos.

PONADER, K.C. \& POTAPOVA, M.G. 2007. Diatoms from the genus Achnanthidium in flowing waters of the Appalachian Mountains (North America): ecology, distribution and taxonomic notes. Limnol. 37:227241.

POTAPOVA, M.A. \& HAMILTON, P.B. 2007. Morphological and ecological variation within the Achnanthidium minutissimum (Bacillariophyceae) species complex. J. Phycol. 43:561-575. http://dx.doi.org/10.1111/j.15298817.2007.00332.x

ROUND, F.E., CRAWFORD, R.M. \& MANN, D.G. 1990. The Diatoms: biology and morphology of the genera. Cambridge University Press, Cambridge. 
RUMRICH, U., LANGE-BERTALOT, H. \& RUMRICH, M. 2000. Diatoms of the Andes. From Venezuela to Patagonia/Tierra del Fuego and two additional contributions. Iconogr. Diatomol. 9:1-673.

SILVA, A.M., LUDWIG, T.A.V., TREMARIN, P.I. \& VERCELLINO, I.S. 2010. Diatomáceas perifíticas em um sistema eutrófico brasileiro (Reservatório do Iraí, estado do Paraná). Acta Bot. Bras. 24(4): no prelo.

SIMONSEN, R. 1974. The diatom plankton of the Indian Ocean Expedition of R/V "Meteor", 1964-65 Meteor Forschungsergebnisse. Reihe D-Biologie. 19:1-66.

TREMARIN, P.I., LUDWIG, T.A.V. \& MOREIRA-FILHO, H. 2008 Eunotia Ehrnberg (Bacillariophyceae) do rio Guaraguaçu, litoral do Paraná. Acta Bot. Bras. 22(3):845-862. http://dx.doi.org/10.1590/S010233062008000300020
TREMARIN, P.I., LUDWIG, T.A.V., BERTOLLI, L.M., FARIA, D.M. \& COSTIN, J.C. 2009. Gomphonema Ehrenberg and Gomphosphenia Lange-Bertalot (Bacillariophyceae) from Maurício river, Paraná, Brazil. Biota Neotropica 9(4):http://www.biotaneotropica.org.br/v9n4/en/abstra ct?inventory+bn00309042009.

TREMARIN, P.I., MOREIRA-FILHO, H. \& LUDWIG, T.A.V. 2010. Pinnulariaceae (Bacillariophyceae) of the Guaraguaçu River, a coastal watershed in Paraná, Brazil. Acta Bot. Bras. 24(2):335-353. http://dx.doi. org/10.1590/S0102-33062010000200005

VYVERMAN, W. 1991. Diatoms from Papua New Guinea. Biblioth. Diatomol. 22:1-223.

WETZEL, R.G. 1983. Limnology. 2nd ed. Saunders College Publishing, New York.

Recebido em 15/12/2010

Versão reformulada recebida em 10/03/2011

Publicado em 29/07/2011 